\title{
Carbon Monoxide Hydrogenation on Activated Carbon Supported Co-Ni Bimetallic Catalysts Via Fischer-Tropsch Reaction to Produce Gasoline
}

\author{
Ahmed Shamil Albazzaz ${ }^{1,2}$, Abdulkareem GhassanAlsultan ${ }^{2}$, Salmiaton Ali $^{1, \text { *, }}$ \\ Yun Hin Taufiq-Yaq, ${ }^{2,}$, Mohamad Amran Mohd Salleh ${ }^{1}$, Wan Azlina Wan Abdul Karim Ghani ${ }^{1}$ \\ ${ }^{1}$ Department of Chemical and Environmental Engineering, University Putra Malaysia, Serdang, Malaysia \\ ${ }^{2}$ Department of Chemistry, Faculty of Science, Universiti Putra Malaysia, Serdang, Malaysia
}

Email address:

taufiq@upm.edu.my (Y. H. Taufiq-Yap), mie@upm.edu.my (S. Ali)

${ }^{*}$ Corresponding author

To cite this article:

Ahmed Shamil Albazzaz, Abdulkareem GhassanAlsultan, Salmiaton Ali, Yun Hin Taufiq-Yaq, Mohamad Amran Mohd Salleh, Wan Azlina Wan Abdul Karim Ghani. Carbon Monoxide Hydrogenation on Activated Carbon Supported Co-Ni Bimetallic Catalysts Via Fischer-Tropsch Reaction to Produce Gasoline. Journal of Energy, Environmental \& Chemical Engineering. Vol. 3, No. 3, 2018, pp. 40-53.

doi: $10.11648 /$ j.jeece. 20180303.11

Received: September 8, 2018; Accepted: September 20, 2018; Published: October 25, 2018

\begin{abstract}
Fischer-Tropsch Synthesis (FTS) is a process which converts synthesized gas (a mixture of H2 and CO) to synthetic liquid fuels and valuable chemicals with the existence of metal catalysts and suitable operational conditions. Less costly and plentiful biomass from agricultural waste can be converted into synthesized gas by thermal gasification. FTS derived Biofuel is a high quality, clean fuel and have a very low sulfur content in comparison to conventional fuel. In this study, FTS reaction was investigated in a tubular fixed bed reactor on prepared Co-Ni bimetallic catalysts supported by walnut shells derived activated carbon (AC) to study the synergistic effect of the active metals on the catalyst's physical properties as well as hydrocarbon liquid product distribution. Employed catalysts were synthesized by wet impregnation method and were characterized afterwards by XRD, TPR-H2, BET surface area and FESEM-EDX techniques to identify the morphology and physical properties of the catalysts. Maximum gasoline selectivity of $69 \%$ was achieved on the $7 \mathrm{Co} 7 \mathrm{Ni} / \mathrm{AC}$ bimetallic catalyst, which was considered as the best bimetallic catalyst among others. Temperature increase from $220^{\circ} \mathrm{C}$ to $300^{\circ} \mathrm{C}$ enhanced gasoline selectivity from $69 \%$ to $92 \%$. In addition, carbon monoxide (CO) conversion increased as well from $43 \%$ to $65 \%$ on the $7 \mathrm{Co} 7 \mathrm{Ni} / \mathrm{AC}$ bimetallic catalyst. On the contrary, increased reaction pressure from 1 bar to 9 bar decreased gasoline selectivity from $92 \%$ to $36 \%$ but increased CO conversion is from $65 \%$ to $84 \%$ on the $7 \mathrm{Co} 7 \mathrm{Ni} / \mathrm{AC}$ bimetallic catalyst. The optimum reaction conditions were considered based on the maximum selectivity of gasoline which was $300^{\circ} \mathrm{C}$ reaction temperature and 1 bar reaction pressure. In conclusion, the employing of bimetallic Co-Ni catalysts supported by $\mathrm{AC}$ in Fischer-Tropsch reaction has significantly enhanced the catalytic activity and improved gasoline selectivity due to the achieved high metal dispersion, better reduction degree and large surface area. Higher reaction temperatures increased gasoline selectivity whereas, higher reaction pressures decreased gasoline selectivity.
\end{abstract}

Keywords: Fischer-Tropsch Synthesis, Clean Energy, Gasoline, Syngas, Bimetallic Catalysts

\section{Introduction}

Hydrogenation of the carbon monoxide takes place through a highly exothermic, heterogeneous catalysed polymerisation reaction that converts syngas into a wide range of organic products (hydrocarbons, oxygenates and some functional groups). The obtained variety of products depends on several factors such as the type of the catalyst and support, conditions of the process represented by the temperature, pressure and the flowrate, but the main products are always n-paraffin and 1-olefin. FTS also forms some minor products such as branched hydrocarbons, 2-olefin and various oxygenate species (alcohols, aldehydes, ketones etc.).

FTS derived liquid fuel is considered as an important 
source for clean energy as well as significant alternative for crude oil derived fuel due to the low sulfur and low lifecycle $\mathrm{CO} 2$ emissions. Many studies have investigated the effect of the employed catalysts and the reaction conditions on the achieved selectivity of the hydrocarbon liquid product fractions. Bechara and colleagues have mentioned that their catalyst $15 \mathrm{Co} / \mathrm{Al} 2 \mathrm{O} 3$ which was tested in a fixed bed reactor, achieved selectivity of $37 \%$ towards light liquid hydrocarbons (gasoline fraction) at a reaction conditions of $180^{\circ} \mathrm{C}$ temperature, 1 bar pressure, $\mathrm{H} 2 / \mathrm{CO}=2$ and $500^{\circ} \mathrm{C}$ reduction temperature. Increase of the reaction temperature to $190^{\circ} \mathrm{C}$ under the same reaction pressure, resulted in enhanced gasoline selectivity to $45 \%$. The ratio of light liquid hydrocarbons (C5_C11) to heavy hydrocarbons (C12_C20) was improved from 0.58 to 0.8 after $10^{\circ} \mathrm{C}$ increase in reaction temperature [1,2]. In different study, it was reported that promoting $\mathrm{Fe} / \mathrm{Mn}$ catalyst with different potassium ratios in the range of $0-3.0$ wt.\% resulted in increased crystallite size of the catalyst and a decrease in BET surface area. The increasing of potassium content retarded the reduction of the catalyst due to the strong interaction of iron oxide with potassium oxide and affected active metal sites [3]. Gasoline content increased from 51 to 59 wt.\% when potassium promotion of $0.2 \mathrm{wt} . \%$ took place, whereas further increase of potassium content $0.7,1.5$ and $3 \mathrm{wt} . \%$, decreased gasoline selectivity to 50, 33 and 25 wt.\% respectively [4]. Reaction was carried out in a fixed bed reactor at operating conditions of $280^{\circ} \mathrm{C}, 1 \mathrm{bar}, \mathrm{H} 2 / \mathrm{CO}=2$ and $250^{\circ} \mathrm{C}$ reduction temperature [5]. CO hydrogenation was also performed on $5 \mathrm{wt} . \%$ cobalt supported on different types of microporous and mesoporous zeolites such as sodium-type zeolites (Na_ZSM-5, Na_beta and faujasite $\mathrm{NaY}$ ) and hydrogen-type zeolite (H_mordenite). Catalytic performance revealed that achieved gasoline fraction selectivity over the mentioned catalysts decreased in the order Co/Na_ZSM-5 $(74 \%)>\mathrm{Co} / \mathrm{Na}$ _beta $(69 \%)>\mathrm{Co} / \mathrm{H}-$ mordenite $(66 \%)>\mathrm{Co} / \mathrm{NaY}(61 \%)$. FT reaction in this study, was carried out in a fixed bed reactor operated at 20 bar, $250^{\circ} \mathrm{C}, \mathrm{H} 2 / \mathrm{CO}=2$ and $400^{\circ} \mathrm{C}$ reduction temperature [6]. Klaigaew and colleagues have studied the effect of catalyst preparation methods on the activation of $\mathrm{Co} / \mathrm{SF}$ for FTS. They prepared their cobalt supported on silica fibre $(\mathrm{Co} / \mathrm{SF})$ catalysts by five different methods which are the wet impregnation (IM), strong electrostatic adsorption (SEA), deposition precipitation (DP) with sodium hydroxide (DPNa) or ammonia (DPNH) solution and hydrothermal method (HT). Reaction was carried out by a fixed bed reactor under reaction conditions of $240^{\circ} \mathrm{C}, 10$ bar and $400^{\circ} \mathrm{C}$. They found that the activity and selectivity of the catalysts were strongly affected by the catalyst preparation method. Catalysts with different particle size of $\mathrm{Co} 3 \mathrm{O} 4$ showed different catalytic activity. Co/SF catalysts prepared by SEA, DPNH and DPNa had the largest $\mathrm{Co} 3 \mathrm{O} 4$ particle size of 9,12 and $14 \mathrm{~nm}$ respectively and were more selective for higher molecular weight hydrocarbons fraction $(\mathrm{C} 12+)$ with values of $22 \%$, $24 \%$ and $25 \%$ respectively; due to the dissociative adsorption of $\mathrm{CO}$, which leads to the formation of the _ $\mathrm{CH} 2$ _ fragments that required for chain growth. Furthermore, the effective participation of olefins in the carbon-carbon chain propagation leading $\alpha$-olefins to re-adsorbed on the catalyst surface and undergo further chain initiation to produce larger hydrocarbons and promote chain growth. Although cobalt particle size in Co/SF-IM is the largest among the four catalysts of $30 \mathrm{~nm}$, it presented the lowest activity and selectivity towards $(\mathrm{C} 12+)$ of only $16 \%$ and highest selectivity to gasoline (C5-C11) of 71\%. On the other hand, the catalyst $\mathrm{Co} / \mathrm{SF}-\mathrm{HT}$ with the smallest crystallite particle size of $4 \mathrm{~nm}$, provided high selectivity to light hydrocarbon products in the range $(\mathrm{C} 5-\mathrm{C} 11)$ of $57 \%$ and very low selectivity to heavy products $(\mathrm{C} 12+)$ of only $3 \%$. The smaller crystallite size particles facilitate the desorption of lighter hydrocarbons than heavier ones [7].

The present work was conducted to study the performance of prepared mono and bimetallic catalyst of $\mathrm{Co}$ and $\mathrm{Ni}$ active metals supported by activated carbon on the Fischer-Tropsch reaction, and to investigate the influence of the corresponding metal loading ratios and operating conditions on the gasoline selectivity and carbon monoxide conversion.

\section{Experimental}

\subsection{Materials Employed}

Walnut (Juglans sp.) shells were collected from Baghdad market, Iraq. Cobalt (II) nitrate hexahydrate $\left(\mathrm{Co}\left(\mathrm{NO}_{3}\right)_{2} \cdot 6 \mathrm{H}_{2} \mathrm{O}\right)$ and nickel (II) nitrate hexahydrate $\left(\mathrm{Ni}\left(\mathrm{NO}_{3}\right)_{2} \cdot 6 \mathrm{H}_{2} \mathrm{O}\right)$ with $99 \%$ purity were obtained from $\mathrm{R} \&$ $\mathrm{M}$ (Malaysia). Nitric acid $\left(\mathrm{HNO}_{3}\right)$ with $65 \%$ purity was purchased from USA (J.T. Baker). The liquid products standard for both alkane and alkene standard n- $\left(\mathrm{C}_{8}-\mathrm{C}_{20}\right)$ and internal standard 1-bromohexane for gas chromatograph (GC) analysis were purchased from Sigma Aldrich. n-Hexane (GC grade) with purity $>98 \%$ was obtained from Merck (USA). Gas mixture cylinders with $99.99 \%$ purity with a composition of (CO: $\mathrm{H}_{2}: \mathrm{N}_{2} 3: 6: 1$, respectively) and $5 \%$ hydrogen gas in argon mixture cylinder $99.99 \%$ purity were supplied by Linde Sdn. Bhd. Malaysia.

\subsection{Catalyst Preparation}

Activated carbon support was prepared using a two-step process: physical and chemical activation. Initially, walnut shells were cleaned and washed several times with water to remove dust and impurities. The washed shells were then dried overnight in an oven at $100^{\circ} \mathrm{C}$. Dry walnut shells were crushed and grinded afterwards into fine powder particles. The powder was sieved through a $200 \mu \mathrm{m}$ metal sieve and then carbonized under $\mathrm{N} 2$ stream up to $700^{\circ} \mathrm{C}$ for $4 \mathrm{~h}$ at a rate of $5^{\circ} \mathrm{C} \mathrm{min}{ }^{-1}$. Prior to the metal precursors introduction, the carbon support is treated with $65 \%$ HNO3 purity reflux at $120^{\circ} \mathrm{C}$ for $12 \mathrm{~h}$ in order to purify it by removing soluble impurities and activate it, followed by thoroughly washing with deionized water through a vacuum filtration process until the solution was neutral. The moist filtrate was finally left to dry in an oven at $100^{\circ} \mathrm{C}$ for $12 \mathrm{~h}$. The catalyst was prepared by wet impregnation of the support with appropriate 
solutions of metal precursors using cobalt nitrate (Co (NO3)2.6H2O) and nickel nitrate (Ni(NO3)2.6H2O) 99.0\% purity, dissolved in deionized water with a maximum metal loading of $15 \%$ weight percent in both monometallic and bimetallic catalysts. After impregnation step, catalyst aqueous solution was left on magnetic stirring overnight with $600-650 \mathrm{rpm}$ agitation. Water removal of the solution was achieved using rotary evaporator at $55-60^{\circ} \mathrm{C}$. Further drying of the catalyst powder was also achieved by means of an oven at $120^{\circ} \mathrm{C}$ overnight and then calcined at $730^{\circ} \mathrm{C}$ for $4 \mathrm{~h}$ under stream of $\mathrm{N} 2$ at a rate of $5^{\circ} \mathrm{C} / \mathrm{min}$. The $\mathrm{AC}$ supported metal catalysts were denoted as $15 \mathrm{Co} / \mathrm{AC}, 15 \mathrm{Ni} / \mathrm{AC}$, $10 \mathrm{Co} 5 \mathrm{Ni} / \mathrm{AC}, 7 \mathrm{Co} 7 \mathrm{Ni} / \mathrm{AC}, 10 \mathrm{Ni} 5 \mathrm{Co} / \mathrm{AC}$.

\subsection{Catalyst Characterization}

X-ray diffraction (XRD) analysis was employed to provide Information about the average metal sizes, phase compositions, crystalline nature and structure of the supported catalysts. XRD analysis was performed using a Shimadzu diffractometer (model XRD-6000). The specific surface area and pore volume of the catalysts were determined by the Brunauer - Emmett -Teller (BET) method using an N2 adsorption/desorption analyser (ThermoFinnigan Sorpmatic 1990 series). The catalysts were degassed overnight at $150^{\circ} \mathrm{C}$ to remove moisture and foreign gases on the surface. Adsorption and desorption process of $\mathrm{N} 2$ on the catalyst surfaces were analysed in a vacuum chamber at $-196^{\circ} \mathrm{C}$. Furthermore, the required reduction temperature to reduce the metal from oxide phase to active phase prior to FTS reaction was determined. This confirmation is required since the metallic phase is the active component for a successful FTS reaction. The reducibility of the catalyst was examined by $\mathrm{H} 2$ temperature programmed reduction (H2-TPR) technique. For this analysis, the Thermo Finnegan TPD/R/O 1100 instrument was used. Basically, the TPR measurements were carried out in a conventional flow system condition with a moisture trap connected to a thermal conductivity detector (TCD). Approximately $20 \mathrm{mg}$ of the sample was placed in a quartz tube reactor with internal diameter of $(6 \mathrm{~mm})$ and then pretreated. Pretreatment step was carried out under the flow of $\mathrm{N} 2$ gas $\left(20 \mathrm{ml} \mathrm{min}^{-1}\right)$ at $150^{\circ} \mathrm{C}$ for $10 \mathrm{~min}$ and the left to cool down to ambient temperature. TPR analysis was performed using mixture of $5 \% \mathrm{H} 2 / \mathrm{Ar}$ with flow of $\left(25 \mathrm{ml} \mathrm{min}^{-1}\right)$ from $60-950^{\circ} \mathrm{C}$ with ramping of $10^{\circ} \mathrm{C} \mathrm{min}^{-1}$. Generally, by using this analysis, the reducibility can be monitored by the hydrogen consumption versus temperature increment. Field emission scanning electron microscopy (FESEM) images were recorded on a LEO 1455 VP electron microscope. The FESEM device was fitted with EDX analysis performed by Rayny EDX-720 spectrometer for determination of $\mathrm{O}, \mathrm{C}, \mathrm{N} 2, \mathrm{Ni}$ and $\mathrm{Co}$.

\subsection{Catalyst Evaluation}

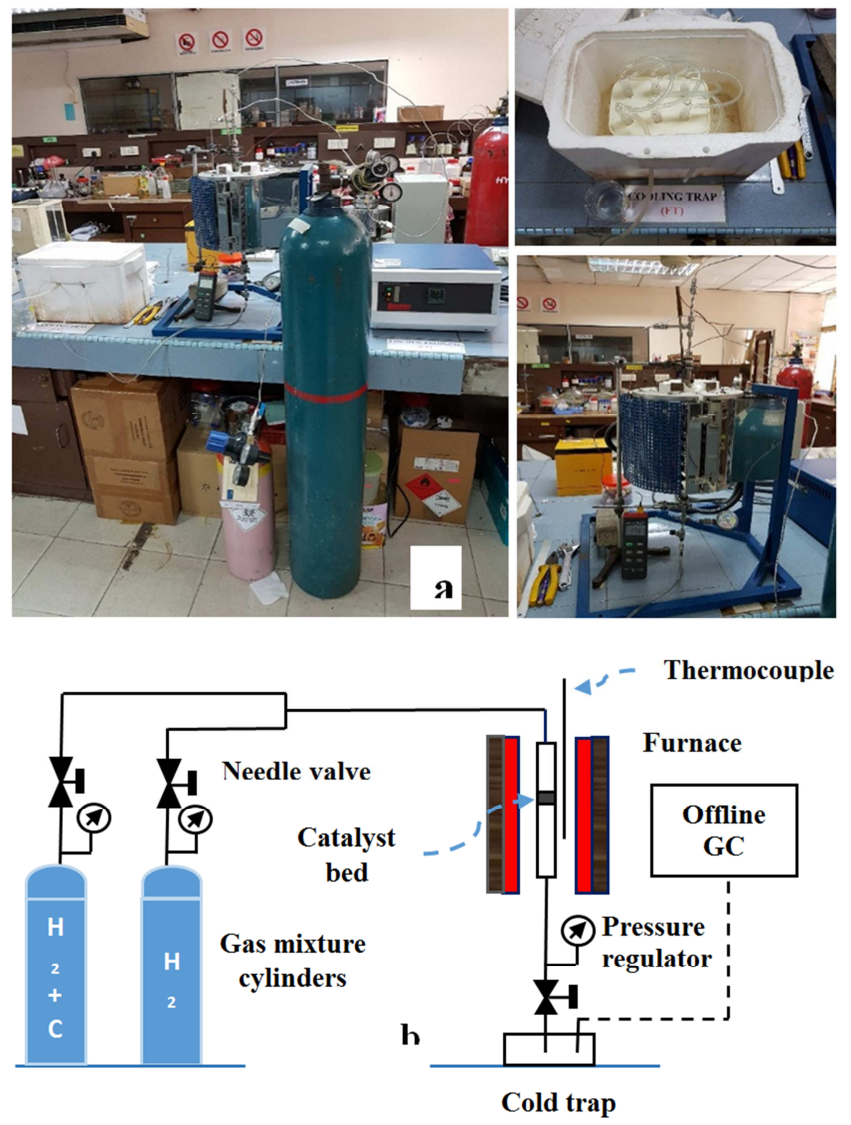

Figure 1. Fischer_Tropsch reaction system : a) The laboratory set up and b) The schematic diagram.

FTS catalytic activity was carried out in a stainless steel fixed bed reactor as shown in Figure 1 (a) and (b). The catalyst was weighed and placed in the middle of the reactor surrounded by glass wool to hold the catalyst and prevent it from moving. After setting up the reaction system, connecting the cold trap and placing the thermocouple in the furnace, the catalyst bed of $1 \mathrm{~g}$ was subjected to a flow of $5 \%$ of Hydrogen in Argon for $5 \mathrm{~h}$ as a pre-treatment stage. The flow rate was maintained at $10 \mathrm{cc} / \mathrm{min}$ under a temperature of $630^{\circ} \mathrm{C}$ to reduce the catalyst from oxide phase to active metal phase prior to FT reaction. Temperature of the reactor was decreased afterwards by reducing the temperature of the furnace to the desired reaction temperature under the flow of hydrogen in order to start the reaction. The flow of hydrogen was then stopped to end the pre-treatment stage and a flow of mixture of reactant gases consists of $\mathrm{CO}, \mathrm{H} 2$ and $\mathrm{N} 2$ was established through the reactor with a flowrate of $10 \mathrm{cc} / \mathrm{min}$ and left for $6 \mathrm{~h}$. The mixture gas with a composition of $\mathrm{CO}$ : $\mathrm{H} 2: \mathrm{N} 2$ 3:6:1, respectively with $\mathrm{N} 2$ being employed as internal standard gas to maintain the desirable ratio $2 / 1$ between $\mathrm{H} 2$ and $\mathrm{CO}$. The produced hydrocarbon gas was condensed through cool ice traps and collected afterwards by small GC vials using hexane (GC grade) with purity $>98 \%$. The unreacted $\mathrm{CO}, \mathrm{H} 2$ and $\mathrm{N} 2$ gases were collected in sampling gas bags. The collected liquid hydrocarbons and the 
unreacted tail gases were sent later for offline analysis using GC-FID Shimadzu QP5050A model and GC-TCD HewlettPackard 6980A model.

\subsection{Product Analysis}

The total product stream was split into two phases; a gaseous phase and liquid phase. The gaseous phase was analysed with a Hewlett-Packard 6980A model gas chromatograph (GC). The gaseous components were $\mathrm{CO}, \mathrm{H}_{2}$, $\mathrm{N}_{2}$, and $\mathrm{CO}_{2}$. The unreacted gaseous components were separated on a Carboxen packed column (support: Carboxen 1000; support size: 80/100 mesh; length/OD: $1.5 \mathrm{~m} \times 1 / 8$ ") and analysed by means of a thermal conductivity detector (TCD). The initial temperature of the oven $\left(35^{\circ} \mathrm{C}\right)$ was maintained for 5 minutes, after which it was increased to $200^{\circ} \mathrm{C}$ at the rate of $3^{\circ} \mathrm{C} / \mathrm{min}$. Once it had reached $200^{\circ} \mathrm{C}$, that temperature was maintained for 60 minutes. The total analysis time was 60 minutes. During this period, all the components of interest were eluted. The synthesized hydrocarbon liquid products were identified using alkane and alkene standards $n-\left(\mathrm{C}_{8}-\mathrm{C}_{20}\right)$, which was obtained from Sigma Aldrich (USA). The liquid products were quantitatively analysed on a gas chromatography (Shimadzu GC-14B) equipped with HP-5 capillary column (length: $30 \mathrm{~m} \times$ inner diameter: $0.32 \mathrm{~mm} \times$ film thickness: $0.25 \mu \mathrm{m}$ ) with a flame ionisation detector (FID) operating at $300^{\circ} \mathrm{C}$. The 1-bromo hexane was used as internal standard for quantitative analysis. An aliquot of $1 \mu \mathrm{L}$ of sample was injected into the GC column. The injection temperature was $250^{\circ} \mathrm{C}$ and nitrogen gas was served as the carrier gas. The initial temperature of the oven was set at $40^{\circ} \mathrm{C}$ and held for $6 \mathrm{~min}$, then ramped to $270^{\circ} \mathrm{C}$, at heating rate of $7^{\circ} \mathrm{C} / \mathrm{min}$. The performances of the catalysts were evaluated by GC-FID in terms of hydrocarbon selectivity [8].

\subsection{Mass Balance Calculation}

The calculations used to determine the mass balance are similar to those used by research thesis [8-12]. The configuration of the experimental set-up used in this study (Figure 1) allows setting the inlet volumetric flowrate, from which the outlet flow rate can be calculated. $\mathrm{N}_{2}$ was used in the reactor feed to serve as an internal standard. As it is an inert gas during the FT reaction, $\mathrm{N}_{2}$ is present only in the feed stream and in the reactor outlet gas stream. The $\mathrm{N}_{2}$ balance across the reactor is therefore expressed as:

$$
\mathrm{F}_{\text {in }} \times \mathrm{X}_{\mathrm{N}_{2, \text { in }}}=\mathrm{F}_{\text {out }} \times \mathrm{X}_{\mathrm{N}_{2, \text { out }}}
$$

Here,

$\mathrm{F}_{\text {in }}=$ total molar flowrate $[\mathrm{mol} / \mathrm{min}]$ of the reactor feed;

$\mathrm{F}_{\text {out }}=$ total molar flowrate $[\mathrm{mol} / \mathrm{min}]$ of the reactor outlet gas stream;

$\mathrm{X}_{\mathrm{N} 2 \text {,in }}=$ molar fraction of nitrogen in the reactor feed;

$\mathrm{X}_{\mathrm{N} 2 \text {,out }}=$ molar fraction of nitrogen in the reactor outlet gas.

The rate of $\mathrm{CO}$ conversion can be calculated as follows:

$$
-\mathrm{r}_{\mathrm{CO}}=\frac{\mathrm{F}_{\mathrm{CO}_{\text {in }}}-\mathrm{F}_{\mathrm{CO}_{\text {out }}}}{\mathrm{m}_{\text {cat }}}
$$

Here,

$\mathrm{F}_{\mathrm{CO}, \text { in }}=$ molar flowrate $[\mathrm{mol} / \mathrm{min}]$ of $\mathrm{CO}$ in the reactor feed;

$\mathrm{F}_{\mathrm{CO} \text {,out }}=$ molar flowrate $[\mathrm{mol} / \mathrm{min}]$ of $\mathrm{CO}$ in the reactor outlet gas;

$\mathrm{m}_{\text {cat }}=$ mass $[\mathrm{gram}]$ of catalyst;

$\mathrm{r}_{\mathrm{CO}}=$ rate of $\mathrm{CO}$ conversion $\left[\mathrm{mol} / \mathrm{min} / \mathrm{g}_{\text {cat }}\right]$.

$$
\begin{gathered}
\mathrm{F}_{\mathrm{CO}_{\text {in }}}=\mathrm{F}_{\text {in }} \times \mathrm{X}_{\mathrm{CO}_{\text {in }}} \\
\mathrm{F}_{\mathrm{CO}_{\text {out }}}=\mathrm{F}_{\text {out }} \times \mathrm{X}_{\mathrm{CO}_{\text {out }}}
\end{gathered}
$$

Where $\mathrm{X}_{\mathrm{CO} \text {,in }}$ and $\mathrm{X}_{\mathrm{CO} \text {,out }}$ are the $\mathrm{CO}$ molar fractions in the reactor feed and outlet gas, respectively.

After introducing expression (3) and (4) in expression (2) and after expressing $F_{\text {in }}$ as a function of $F_{\text {out }}$ using equation (1), the rate of CO consumption rate was expressed as:

$$
-\mathrm{r}_{\mathrm{CO}}=\frac{\mathrm{F}_{\text {out }} \times\left[\mathrm{X}_{\mathrm{CO}_{\text {in }}} \times\left(\frac{\mathrm{x}_{\mathrm{N}_{2, \text { out }}}}{\mathrm{X}_{\mathrm{N}_{2 . \text { in }}}}\right)-\mathrm{X}_{\mathrm{CO}, \text { out }}\right]}{\mathrm{m}_{\text {cat }}}
$$

In present study, Equation (6), given below, was used to calculate the rate of $\mathrm{CO}$ conversion directly, as $\mathrm{X}_{\mathrm{CO} \text {,in }}$ and $\mathrm{X}_{\mathrm{N} 2}$, in were known from the premixed gas cylinder and $\mathrm{X}_{\mathrm{CO}}$, out and $\mathrm{X}_{\mathrm{N} 2}$, out were derived from the reactor outlet gas analysis. $F_{\text {out }}$ was also calculated from the total gas volumetric flow rate at the reactor exit by assuming the ideal gas law.

The CO conversion was calculated as follows:

$$
\% \mathrm{CO}_{\text {conv }}=\frac{\left[\mathrm{X}_{\mathrm{CO}_{\text {in }}}-\mathrm{X}_{\mathrm{CO}_{\text {out }}} \times\left(\frac{\mathrm{x}_{\mathrm{N}_{2, \text { in }}}}{\mathrm{x}_{\mathrm{N}_{2 . \text { out }}}}\right)\right] \times 100}{\mathrm{X}_{\mathrm{CO}_{\text {in }}}}
$$

The product selectivity for hydrocarbons $\mathrm{S}_{\mathrm{i}}$ was calculated for component $\mathrm{x}_{\mathrm{i}}$ as follows:

$$
\mathrm{S}_{\mathrm{i}}=\left[\frac{\text { mass component } \mathrm{X}_{\mathrm{i}}}{\sum \mathrm{X}_{\mathrm{i}}}\right] \times 100 \%
$$

\section{Results and Discussion}

\subsection{Catalyst Characterization}

X_ray diffraction patterns of the synthesized carbon, doped cobalt and nickel mono and bimetallic catalysts $(15 \mathrm{Ni} / \mathrm{AC}$, $15 \mathrm{Co} / \mathrm{AC}, 10 \mathrm{Ni} 5 \mathrm{Co} / \mathrm{AC}, 10 \mathrm{Co} 5 \mathrm{Ni} / \mathrm{AC}$ and $7 \mathrm{Co} 7 \mathrm{Ni} / \mathrm{AC})$ after calcination at $730^{\circ} \mathrm{C}$ for $4 \mathrm{~h}$ are shown in Figures 2 and 3 respectively. The XRD diffractogram of raw carbonized walnut shells and acid treated carbon samples showed an amorphous structure at around $2 \theta$ of $25^{\circ}$, which is a typical characteristic of activated carbon [13, 14]. The amorphous structure of carbonized walnut shells was drastically increased after acid refluxed and thermal activation treatment, which proves the great effect that has been given on the structure of the carbon after those two steps. Furthermore, it was also found that applying thermal activation after acid treatment has influenced positively the crystallinity of the carbon where, diffraction peaks of carbon at $2 \theta$ of $25^{\circ}, 44^{\circ}, 64.5^{\circ}$, and $77.5^{\circ}$ became narrower after 
treatment indicating the high crystallinity of the synthesized carbon as shown in Figure 2 (b). A high level of crystallized graphitic structure for carbon material would facilitate the electron transfer between the FT active metal and CO molecule and hence be conducive for the CO activation [15]. Crystallite size was determined by Debye-Scherrer equation and was found decreased after acid treated and thermal activation step. Crystallite size of $\mathrm{a}$ and $\mathrm{b}$ is $43.8 \mathrm{~nm}$ and 14.1 $\mathrm{nm}$, respectively [16]. The monometallic $15 \mathrm{Co} / \mathrm{AC}$ sample exhibited the pattern of $\left(\mathrm{Co}_{3} \mathrm{O}_{4}\right)$ spinel at $2 \theta$ values of $36.7^{\circ}$ and $74^{\circ}$ JCPDS \# 00-009-0418 [15, 17] as well as the pattern of cobalt oxide phase $(\mathrm{CoO})$ at $2 \theta$ of $42.5^{\circ}$ and $61.5^{\circ} \mathrm{JCPDS}$ \# 00-001-1227. In addition, $2 \theta$ value of $51.5^{\circ}$ was noticed to show the pattern of $\left(\mathrm{Ni}_{2} \mathrm{O}_{3}\right)$ phase on the sample $15 \mathrm{Ni} / \mathrm{AC}$ JCPDS \# 00-014-0481 [18, 19] as well as the pattern of nickel oxide phase (NiO) at $2 \theta$ of $76^{\circ}$ JCPDS \# 01-073-1519. Regarding bimetallic samples $10 \mathrm{Ni} 5 \mathrm{Co} / \mathrm{AC}, 10 \mathrm{Co} 5 \mathrm{Ni} / \mathrm{AC}$ and $7 \mathrm{Co} 7 \mathrm{Ni} / \mathrm{AC}$, diffraction lines of $\left(\mathrm{Co}_{3} \mathrm{O}_{4}\right)$ spinel phase and $(\mathrm{CoO})$ phase were identified at $2 \theta$ values of $36.7^{\circ}, 42.5^{\circ}$, $61.5^{\circ}$ and $74^{\circ}$ on the three bimetallic samples except for the catalyst $10 \mathrm{Ni} 5 \mathrm{Co} / \mathrm{AC}$ which did not show a peak at the value of $74^{\circ}$ because of either well dispersion of the metal precursor into the support or the low loading percent of cobalt precursor in the catalyst [17, 20]. Furthermore, the diffraction patterns of $\left(\mathrm{Ni}_{2} \mathrm{O}_{3}\right)$ and $(\mathrm{NiO})$ phases were noticed on the three bimetallic catalysts at $2 \theta$ of $51.5^{\circ}$ and $76^{\circ}$. Bimetallic mixed oxides $\left(\mathrm{NiCo}_{2} \mathrm{O}_{4}\right)$ were also detected at $2 \theta$ of $36.7^{\circ}, 44^{\circ}, 64.5^{\circ}$ and 77.5 JCPDS \# 00-020-0781 on the three bimetallic catalysts .

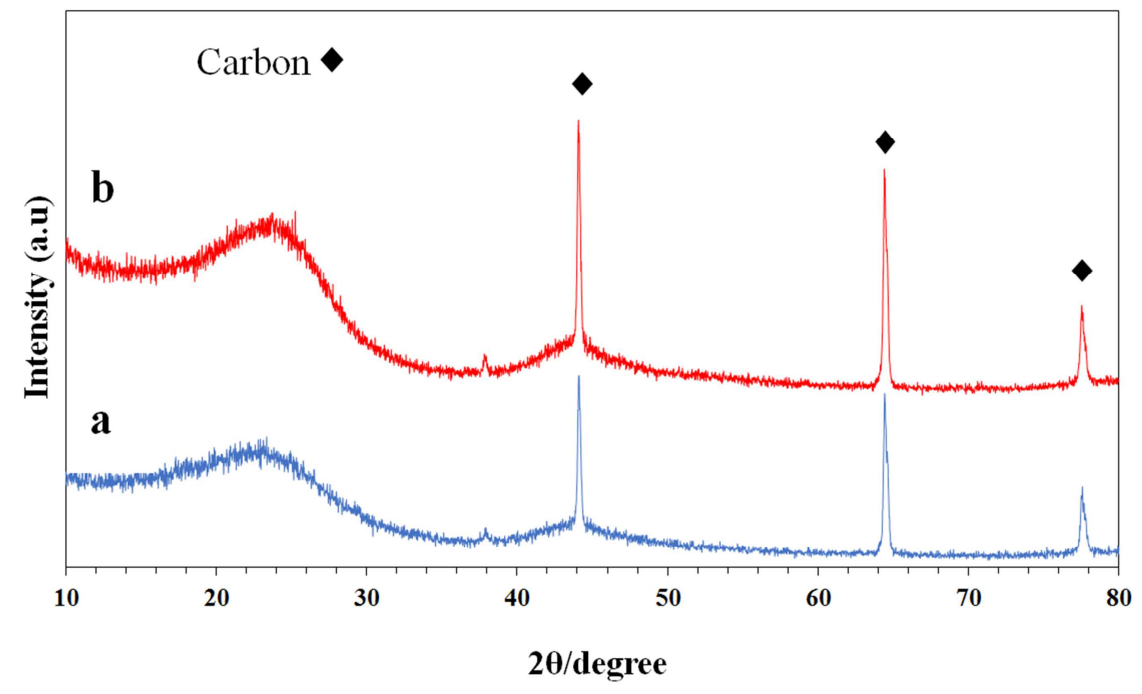

Figure 2. XRD diffraction patterns for : (a) Raw AC and (b) Treated and calcined AC.

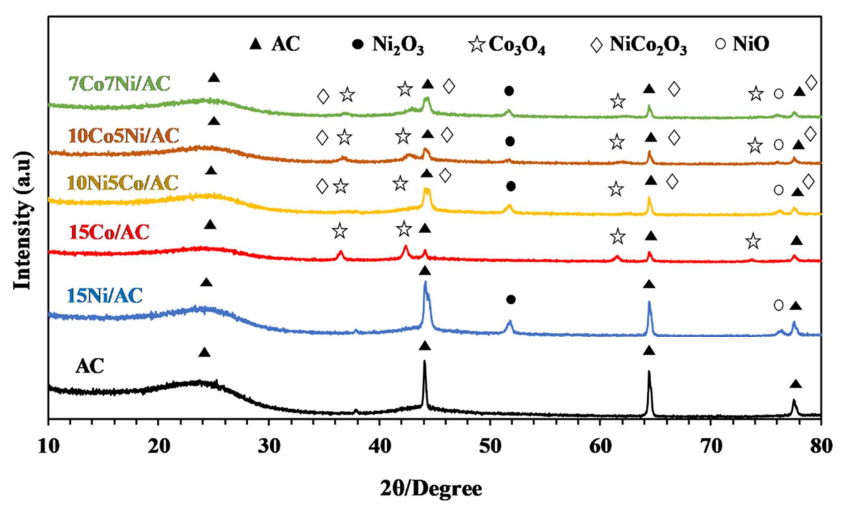

Figure 3. XRD diffraction patterns for the support and Co-Ni bimetallic catalysts.

The average crystallite size for cobalt-nickel bimetallic catalysts were calculated from the line broadening XRD patterns of the most intense peak intensity using DebyeScherrer equation as listed in Table 1 . The average crystallite size decreased from the highest values of $12.9 \mathrm{~nm}$ and 12.6 $\mathrm{nm}$ on the monometallic catalyst $15 \mathrm{Ni} / \mathrm{AC}$ and $15 \mathrm{Co} / \mathrm{AC}$, respectively to lower values of $10.7 \mathrm{~nm}, 9.8 \mathrm{~nm}$ and $9.6 \mathrm{~nm}$ on the bimetallic catalysts $10 \mathrm{Co} 5 \mathrm{Ni} / \mathrm{AC}, 7 \mathrm{Co} 7 \mathrm{Ni} / \mathrm{AC}$ and
$10 \mathrm{Ni} 5 \mathrm{Co} / \mathrm{AC}$, respectively. Results of crystallite sizes indicated a better dispersion of the bimetallic catalysts into the support in comparison to the monometallic catalysts as they possess the smallest crystallite sizes, reflecting the positive effect of incorporating two active metals in a single bimetallic catalyst. Increase of Ni loading from 5 to 7 and 10 wt.\% has decreased crystallite size and enhanced dispersion for the bimetallic catalysts $10 \mathrm{Co} 5 \mathrm{Ni} / \mathrm{AC}, 7 \mathrm{Co} 7 \mathrm{Ni} / \mathrm{AC}$ and $10 \mathrm{Ni} 5 \mathrm{Co} / \mathrm{AC}$, respectively. Similar results were also reported by others $[21,22]$ over nickel promoted $\mathrm{Fe} / \mathrm{SiO}_{2}$ catalyst and Fe-Ni bimetallic catalyst, respectively [23]. They reported that the increase of nickel addition improved the dispersion of iron oxides, leading to an increase in BET surface area of bimetallic catalyst and formation of metal oxides with small crystallite sizes. Furthermore, the incorporation of $\mathrm{Co}$ and $\mathrm{Ni}$ in a bimetallic catalyst has also led to decrease the oxide particle size from $17.5 \mathrm{~nm}$ on the monometallic $6 \mathrm{Co} / \mathrm{SiO}_{2}$ and $6 \mathrm{Ni} / \mathrm{SiO}_{2}$ to $14.4 \mathrm{~nm}$ and $12.7 \mathrm{~nm}$ on the bimetallic $3 \mathrm{Co} 3 \mathrm{Ni} / \mathrm{SiO}_{2}$ and $6 \mathrm{Co} 6 \mathrm{Ni} / \mathrm{SiO}_{2}$, respectively. Increasing $\mathrm{Ni}$ loading to maximum limit of $6 \mathrm{wt} . \%$ has decreased crystallite size to smaller value of $12.7 \mathrm{~nm}$ [24]. 
Table 1. Average crystallite size for Co-Ni bimetallic catalysts.

\begin{tabular}{ll}
\hline Catalyst & Crystallite Size (nm) \\
\hline $15 \mathrm{Ni} / \mathrm{AC}$ & 12.9 \\
$15 \mathrm{Co} / \mathrm{AC}$ & 12.6 \\
$10 \mathrm{Ni} 5 \mathrm{Co} / \mathrm{AC}$ & 9.6 \\
$10 \mathrm{Co} 5 \mathrm{Ni} / \mathrm{AC}$ & 10.7 \\
$7 \mathrm{Co} 7 \mathrm{Ni} / \mathrm{AC}$ & 9.8 \\
\hline
\end{tabular}

${ }^{\text {a }}$ Crystallite Size is obtained by Debye-Scherrer equation from XRD

The reducibility of the calcined catalysts was investigated by temperature programmed reduction in hydrogen environment (TPR- $\left.\mathrm{H}_{2}\right)$. Those experiments determine the appropriate reduction temperatures for catalysts in pretreatment step. TPR profiles for mono and bimetallic catalysts were investigated and shown in Figure 4. Catalyst $15 \mathrm{Co} / \mathrm{AC}$ showed two different hydrogen consumption peaks which appeared at $490^{\circ} \mathrm{C}$ and $573^{\circ} \mathrm{C}$. Those peaks were assigned to the reduction process of cobalt oxide phase $\mathrm{Co}_{3} \mathrm{O}_{4}$ (tri-cobalt tetroxide) into active metal phase as follow: $\mathrm{Co}_{3} \mathrm{O}_{4} \rightarrow \mathrm{CoO} \rightarrow \mathrm{Co}^{\circ}[25]$. Catalyst $15 \mathrm{Ni} / \mathrm{AC}$ showed two hydrogen consumption peaks as well. The two hydrogen consumption peaks appeared at $296^{\circ} \mathrm{C}$ and $597^{\circ} \mathrm{C}$ and were attributed to the reduction of nickel oxide phase $\mathrm{Ni}_{2} \mathrm{O}_{3}$ (nickel trioxide) into active metal phase as follow: $\mathrm{Ni}_{2} \mathrm{O}_{3} \rightarrow$ $\mathrm{NiO} \rightarrow \mathrm{Ni}^{\circ}$ [26]. All bimetallic samples $7 \mathrm{Co} 7 \mathrm{Ni} / \mathrm{AC}$, $10 \mathrm{Ni} 5 \mathrm{Co} / \mathrm{AC}$ and $10 \mathrm{Co} 5 \mathrm{Ni} / \mathrm{AC}$ displayed lower reduction temperatures at $516^{\circ} \mathrm{C}, 524^{\circ} \mathrm{C}$ and $565^{\circ} \mathrm{C}$, respectively, than both cobalt and nickel metals in their monometallic form which were $573^{\circ} \mathrm{C}$ and $597^{\circ} \mathrm{C}$ for $15 \mathrm{Co} / \mathrm{AC}$ and $15 \mathrm{Ni} / \mathrm{AC}$, respectively, suggested an easier reduction process [27]. Studies have showed that cobalt has the ability to minimize the reduction temperature when it is incorporated with second metal in a bimetallic system catalyst [28].

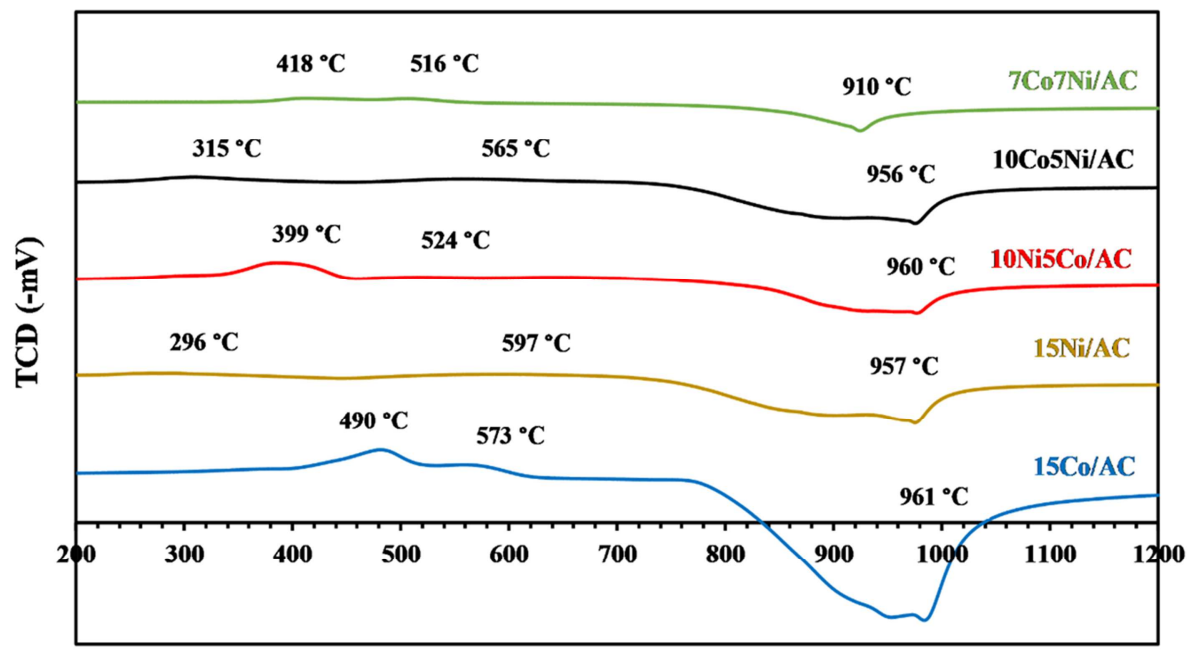

Temperature ${ }^{\circ} \mathrm{C}$

Figure 4. TPR profiles for Co-Ni bimetallic catalysts.

The Degree of reduction and the amount of hydrogen consumption during TPR are given in Table 2. Degree of reduction $\left(D_{r}\right)$ is described in Equation (8) and defined as the ratio of consumed hydrogen for the complete reduction of metal oxides to the amount of hydrogen calculated for this complete reduction [29].

$$
\mathrm{D}_{\mathrm{r}}(\%)=\frac{\mathrm{H} 2 \text { consumption }(\mu \mathrm{mol} / \mathrm{g})(\text { peak } 1+\text { peak } 2)}{\text { Total } \mathrm{H} 2 \text { consumption }(\mu \mathrm{mol} / \mathrm{g})}
$$

Hydrogen consumption and reduction degree for the catalysts are listed in Table 2. The hydrogen intake for monometallic $15 \mathrm{Co} / \mathrm{AC}$ and $15 \mathrm{Ni} / \mathrm{AC}$ was found to be $2883 \mu \mathrm{mol} / \mathrm{g}$ and 2483 $\mu \mathrm{mol} / \mathrm{g}$, respectively. The incorporation of the two active metals $\mathrm{Co}$ and $\mathrm{Ni}$ in the bimetallic catalyst has decreased the hydrogen consumption for all binary catalyst system to values of 1747 , 1821 and $1446 \mu \mathrm{mol} / \mathrm{g}$ for the bimetallic catalysts $10 \mathrm{Co} 5 \mathrm{Ni} / \mathrm{AC}$, $10 \mathrm{Ni} 5 \mathrm{Co} / \mathrm{AC}$ and $7 \mathrm{Co} 7 \mathrm{Ni} / \mathrm{AC}$, respectively in comparison to monometallic catalysts. The catalyst $7 \mathrm{Co} 7 \mathrm{Ni} / \mathrm{AC}$ was found to consume the minimum amount of $\mathrm{H}_{2}$ of $1446 \mu \mathrm{mol} / \mathrm{g}$. The degree of reduction was $58 \%$ and $54 \%$ for monometallic catalysts $15 \mathrm{Co} / \mathrm{AC}$ and $15 \mathrm{Ni} / \mathrm{AC}$, respectively. Whereas, the binary system catalysts revealed enhanced reducibility to values of $61 \%, 67 \%$ and $72 \%$ for the samples $10 \mathrm{Co} 5 \mathrm{Ni} / \mathrm{AC}$, $10 \mathrm{Ni} 5 \mathrm{Co} / \mathrm{AC}$ and $7 \mathrm{Co} 7 \mathrm{Ni} / \mathrm{AC}$, respectively. The enhanced reducibility of the bimetallic $7 \mathrm{Co} 7 \mathrm{Ni} / \mathrm{AC}$ was believed to be due to the high surface area it possesses $\left(483 \mathrm{~m}^{2} / \mathrm{g}\right)$, as well as relatively big pore volume $(2.7 \mathrm{~nm})$ compared to other catalysts which facilitates the diffusion and adsorption process of the reactant gases on the surface and in the support pores causing a better reaction with the active metal phases. Furthermore, smaller sizes of metal crystallite suggested a well dispersion into the support and easier reduction into active metal phases [15]. In elsewhere study, reduction temperatures have also decreased from $350^{\circ} \mathrm{C}$ and $570^{\circ} \mathrm{C}$ on pure iron catalyst to lower values of $250^{\circ} \mathrm{C}$ and $365^{\circ} \mathrm{C}$ on $\mathrm{Ni}$ promoted iron catalyst, suggested an easier reduction process from $\mathrm{Fe}_{2} \mathrm{O}_{3}$ oxide phase to $\mathrm{Fe}$ active metal phase, which was provided by the synergistic effect of $\mathrm{Ni}$ and Fe active metals. The study mentioned that reduction peaks of the catalysts were shifted to lower temperatures with the increase of nickel content, indicated that the incorporation of nickel improves the catalyst reduction rate in $\mathrm{H}_{2}$. The decrease in reduction temperatures was ascribed to the fact that the 
crystallite size of iron oxides is decreased with the increase of the catalyst nickel content, since iron oxide with little crystallite size can be easily reduced. Furthermore, due to the presence of metallic nickel, the hydrogen spill over from nickel metal to iron oxide might take place and promote the reduction of iron oxide [22]. Similar behaviours from Ni active metal on the reduction temperatures and crystallite size were also reported by Rytter and colleagues [30].

$\mathrm{N}_{2}$ adsorption-desorption was carried out to characterize the textural properties of the support and the corresponding supported catalysts. As shown in Figure 5 A, the isotherm of activated carbon was found to agree with type I isotherm exhibiting a hysteresis loop type $\mathrm{H} 4$ which is according to the IUPAC classification, indicating the characteristic of micro and mesoporous material [15]. It is worth noting that the shape of the impregnated catalyst isotherm in Figure $5 \mathrm{~B}$ remained almost identical to that of AC support, suggesting that AC support structure did not suffer any significant change after metal incorporation. The structural parameters of the support and catalysts are listed in Table 3. BET surface area and pore volume measured after carbonization was 381 $\mathrm{m}^{2} / \mathrm{g}$ and $0.259 \mathrm{~cm}^{3} / \mathrm{g}$, respectively, whereas the carbon exhibited larger surface area and pore volume of $532 \mathrm{~m}^{2} / \mathrm{g}$ and $0.305 \mathrm{~cm}^{3} / \mathrm{g}$, respectively after acid treatment and calcination. The significant increase in surface area was attributed to the effect of acid which gave a special kind of defect on the carbon surface led to extreme change in the structure morphology and hence improved the surface area of the support [31]. A decrease was noticed in the surface area and pore volume of the support after impregnating metal precursors into the support. This can be attributed to the excess of active metals embedded into the channel of parent materials and incorporated into the pore of $\mathrm{AC}$ causing pores blockage [32]. All impregnated and calcined catalysts presented larger pore diameters than their corresponding support which can be attributed to the dispersion of metal oxide particles on the support surface as well as the porous structure of these oxides [15].

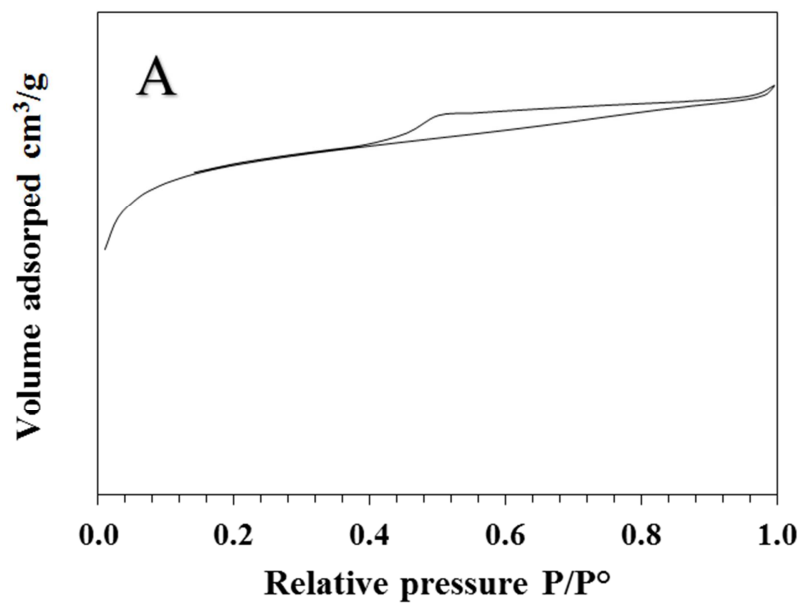

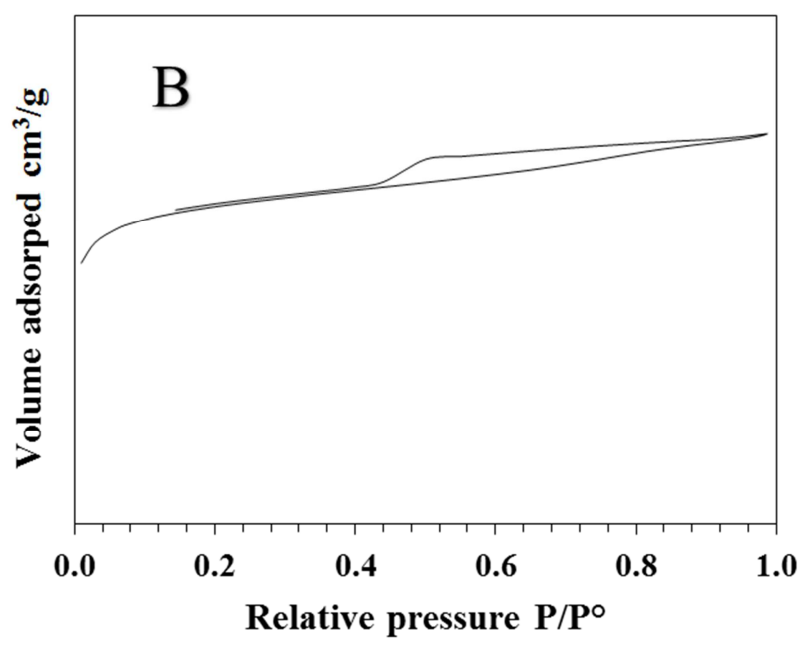

Figure 5. $\mathrm{N}_{2}$ adsorption/desorption isotherms for (A) treated and calcined $A C$ and (B) AC supported bimetallic catalyst.
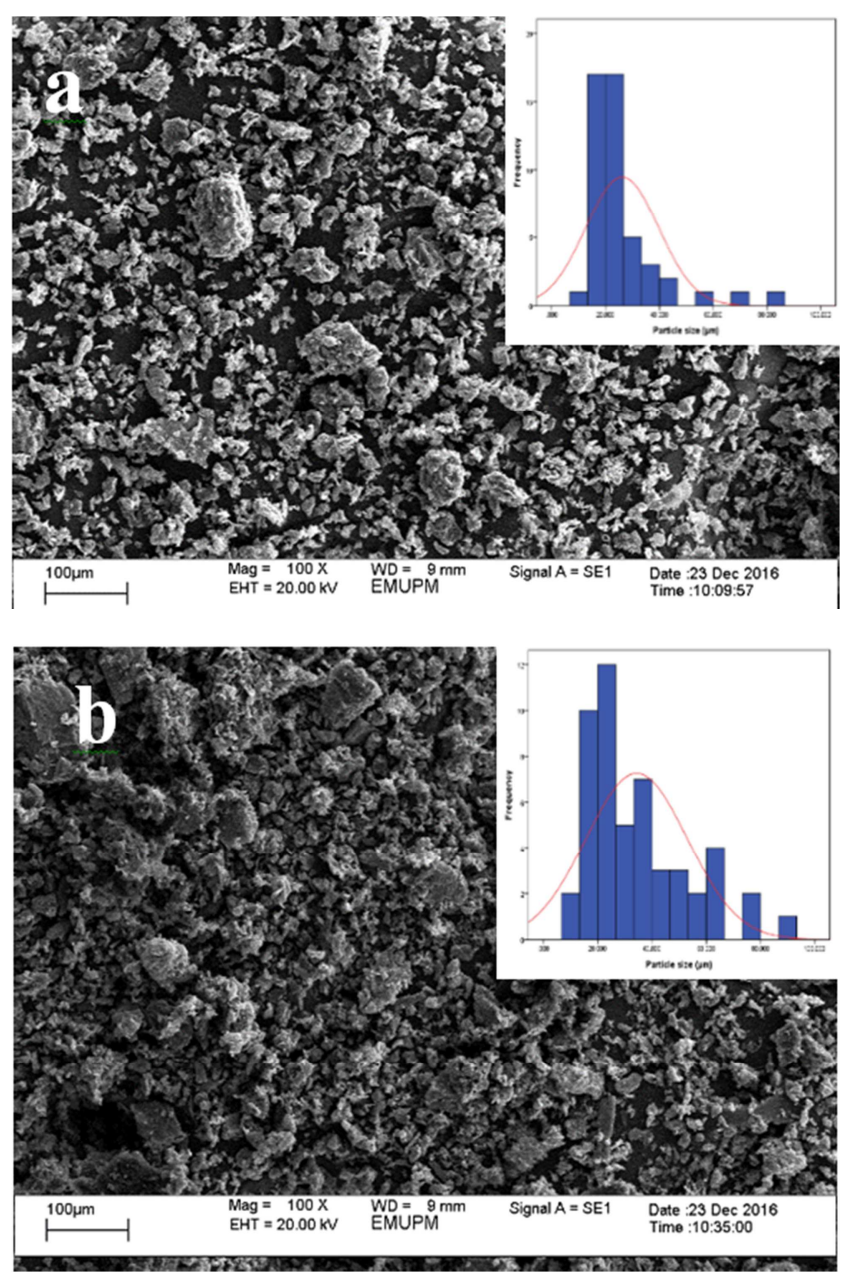


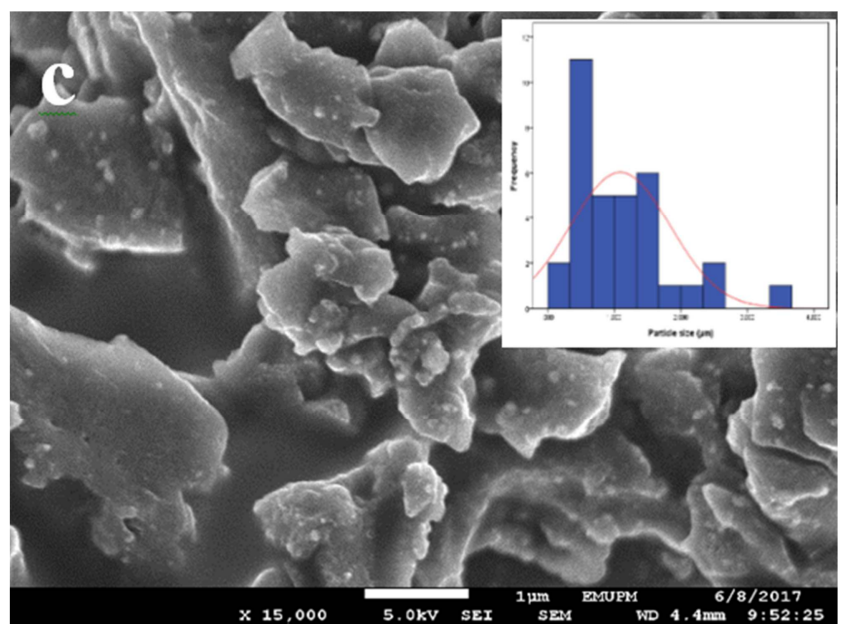

Figure 6. Morphological feature of the prepared catalysts : a) Carbonized walnut shells, b) Acid treated $A C$, c) Calcined $7 \mathrm{Co} 7 \mathrm{Ni} / \mathrm{AC}$.

Morphological features of the solid catalysts were also studied to investigate the geometry structure, pattern and particles shape on catalysts' solid surface. SEM images for raw carbonized walnut shells, acid treated carbon and FESEM images of calcined 7Co7Ni/AC bimetallic catalysts were characterized and shown in Figure 6. The carbonized sample in Figure 6 (a) exhibited rough block carbon with considerably random and irregular shaped structure morphology, whereas acid treated carbon in Figure 6 (b) revealed a denser, self-assembled, aggregated and softer structure. The defection of the carbon support surface after acid treatment helps as anchoring site for metal particles [31]. FESEM images of the bimetallic catalysts $7 \mathrm{Co} 7 \mathrm{Ni} / \mathrm{AC}$ showed a uniform distribution of the metal oxides on the support as shown in Figure 6 (c). Particles size and shape were dramatically changed after the fresh walnut shell experienced chemical activation step. It can be observed that the preparation condition has a great influence on morphology of the carbon. Particles diameters for the most abundant ones of both raw carbonized shells and acid treated carbon were observed ranging from $(20-40 \mu \mathrm{m})$ as shown in Figure 6 (a) and (b). whereas, particles diameters have decreased on the calcined impregnated bimetallic catalysts to $(1-3 \mu \mathrm{m})$ as shown in Figure 6 (c). High performance catalysts are usually consisting of high surface area materials. It was shown that particle size, shape and porosity of catalyst are influencing the reaction activity greatly. Therefore, possessing very small particles of highly-ordered porous support would provide a high surface area and large active site for the catalysts, offering a beneficial effect towards the reaction activity [14]. The elemental composition of the prepared catalyst was investigated by EDX analysis as shown in Table 4.

Table 2. Hydrogen consumptions and reduction degrees for Co-Ni catalysts.

\begin{tabular}{|c|c|c|c|c|c|c|c|}
\hline \multirow[b]{2}{*}{ Catalysts } & \multicolumn{4}{|c|}{$\mathrm{H}_{2}$-Consumption $(\mu \mathrm{mol} / \mathrm{g})^{\mathrm{a}}$} & \multicolumn{3}{|c|}{ Reduction Degree\% ${ }^{b}$} \\
\hline & Peak 1 & Peak 2 & Peak 3 & Total & Peak 1 & Peak 2 & Dr\% \\
\hline $15 \mathrm{Co} / \mathrm{AC}$ & 892 & 780 & 1211 & 2883 & 31 & 27 & 58 \\
\hline $10 \mathrm{Co} 5 \mathrm{Ni} / \mathrm{AC}$ & 538 & 545 & 664 & 1747 & 30 & 31 & 61 \\
\hline 7Co7Ni/AC & 518 & 523 & 405 & 1446 & 36 & 36 & 72 \\
\hline $10 \mathrm{Ni} 5 \mathrm{Co} / \mathrm{AC}$ & 632 & 588 & 601 & 1821 & 35 & 32 & 67 \\
\hline $15 \mathrm{Ni} / \mathrm{AC}$ & 689 & 652 & 1142 & 2483 & 28 & 26 & 54 \\
\hline
\end{tabular}

${ }^{\mathrm{a}} \mathrm{H}_{2}$-consumption is obtained from TPR ${ }^{\mathrm{b}}$ Reduction Degree is obtained from TPR

Table 3. Structural parameters of the support and the catalysts.

\begin{tabular}{lccl}
\hline Catalyst & BET surface area $\mathbf{~ m}^{2} / \mathbf{g}$ & Pore volume $\mathbf{~ c m}^{\mathbf{3}} / \mathbf{g}$ & Pore width $\mathbf{n m}$ \\
\hline Carbonized Shells & 381 & 0.259 & 2.8 \\
Treated calcined AC & 532 & 0.305 & 2.3 \\
$15 \mathrm{Co} / \mathrm{AC}$ & 384 & 0.243 & 2.4 \\
$10 \mathrm{Co} 5 \mathrm{Ni} / \mathrm{AC}$ & 433 & 0.266 & 2.6 \\
$7 \mathrm{Co} 7 \mathrm{Ni} / \mathrm{AC}$ & 483 & 0.296 & 2.7 \\
$10 \mathrm{Ni5Co} / \mathrm{AC}$ & 456 & 0.283 & 2.6 \\
$15 \mathrm{Ni} / \mathrm{AC}$ & 395 & 0.239 & 2.5 \\
\hline
\end{tabular}

Table 4. Elemental composition of the catalysts.

\begin{tabular}{llllll}
\hline \multirow{2}{*}{ Catalyst $^{\mathbf{a}}$} & \multicolumn{7}{l}{ Elemental Composition\% } \\
\cline { 2 - 6 } & $\mathbf{C}$ & $\mathbf{N}$ & $\mathbf{O}$ & $\mathbf{C o}$ & $\mathbf{N i}$ \\
\hline AC & 100 & - & - & - & - \\
Acid Treated AC & 82.36 & 4.72 & 12.92 & - & - \\
7Co7Ni/AC & 62.11 & - & 23.09 & 6.81 & 7.99 \\
\hline
\end{tabular}

${ }^{\text {a }}$ Theoretical weight ratio of the catalysts

${ }^{\mathrm{b}}$ Experimental weight ratio of the catalysts from EDX

\subsection{Catalytic Activity and the Effect of Bimetallic Catalyst}

In order to investigate the effect of different metal loading ratios of Co-Ni group of catalysts on catalytic activity and product selectivity, five different mono and bimetallic catalysts were prepared with different metal loading ratios. The prepared catalysts were denoted as $15 \mathrm{Co} / \mathrm{AC}$, $10 \mathrm{Co} 5 \mathrm{Ni} / \mathrm{AC}, 7 \mathrm{Co} 7 \mathrm{Ni} / \mathrm{AC}, 10 \mathrm{Ni} 5 \mathrm{Co} / \mathrm{AC}$ and $15 \mathrm{Ni} / \mathrm{AC}$. It was revealed from XRD and TPR analysis (Tables 1 and 2, respectively) that the incorporation of $\mathrm{Ni}$ and $\mathrm{Co}$ active 
metals into bimetallic catalysts has enhanced the quality of the catalysts in terms of minimizing oxide crystallite size and reducibility of the catalyst. The size of crystallite particle was reduced from $12.9 \mathrm{~nm}$ and $12.6 \mathrm{~nm}$ on monometallic catalysts $15 \mathrm{Ni} / \mathrm{AC}$ and $15 \mathrm{Co} / \mathrm{AC}$, respectively to $10.7 \mathrm{~nm}$, $9.8 \mathrm{~nm}$ and $9.6 \mathrm{~nm}$ on the bimetallic catalysts $10 \mathrm{Co} 5 \mathrm{Ni} / \mathrm{AC}$, $7 \mathrm{Co} 7 \mathrm{Ni} / \mathrm{AC}$ and $10 \mathrm{Ni} 5 \mathrm{Co} / \mathrm{AC}$, respectively. Indicating better dispersion into the support and hence, improved reducibility of the catalyst $[22,33,34]$. Reduction degree has decreased in the order of $7 \mathrm{Co} 7 \mathrm{Ni} / \mathrm{AC}(72 \%)>10 \mathrm{Ni} 5 \mathrm{Co} / \mathrm{AC}(67 \%)>$ $10 \mathrm{Co} 5 \mathrm{Ni} / \mathrm{AC}(61 \%)>15 \mathrm{Co} / \mathrm{AC}(58 \%)>15 \mathrm{Ni} / \mathrm{AC}(54 \%)$. Smaller oxide particles were dispersed easily into the support resulted in better reduction degree and thus enhanced catalytic activity $[21,24,30]$. Increasing $\mathrm{Ni}$ metal loading ratio from $5 \mathrm{wt} . \%$ to 7 and $10 \mathrm{wt} . \%$ in the Co-Ni bimetallic catalysts has resulted in enhancing BET surface area as follows: 7Co7Ni/AC $\left(483 \mathrm{~m}^{2} / \mathrm{g}\right)>10 \mathrm{Ni} 5 \mathrm{Co} / \mathrm{AC}\left(456 \mathrm{~m}^{2} / \mathrm{g}\right)>$ $10 \mathrm{Co} 5 \mathrm{Ni} / \mathrm{AC}\left(433 \mathrm{~m}^{2} / \mathrm{g}\right)$ due to the better dispersion of metal particles which was offered by mixing $\mathrm{Co}$ and $\mathrm{Ni}$ active metals [35]. The enhanced reducibility of the bimetallic $7 \mathrm{Co} 7 \mathrm{Ni} / \mathrm{AC}$ was believed to be due to the high surface area the catalyst possesses, as well as relatively big pore volume in comparison to other catalysts which facilitated the diffusion and adsorption process of the reactant gases on the surface and in the support pores causing a better reaction with the active metals phase. Furthermore, smaller sizes of metal crystallite suggested a well dispersion into the support and easier reduction into active metal phase [15]. CO conversion was the maximum on the bimetallic catalyst $7 \mathrm{Co} 7 \mathrm{Ni} / \mathrm{AC}(43 \%)$ and decreased in the order of $10 \mathrm{Ni} 5 \mathrm{Co} / \mathrm{AC}(32 \%)>10 \mathrm{Co} 5 \mathrm{Ni} / \mathrm{AC}(31 \%)>15 \mathrm{Co} / \mathrm{AC}$ $(26 \%)>15 \mathrm{Ni} / \mathrm{AC}(24 \%)$ as shown in Figure 7.

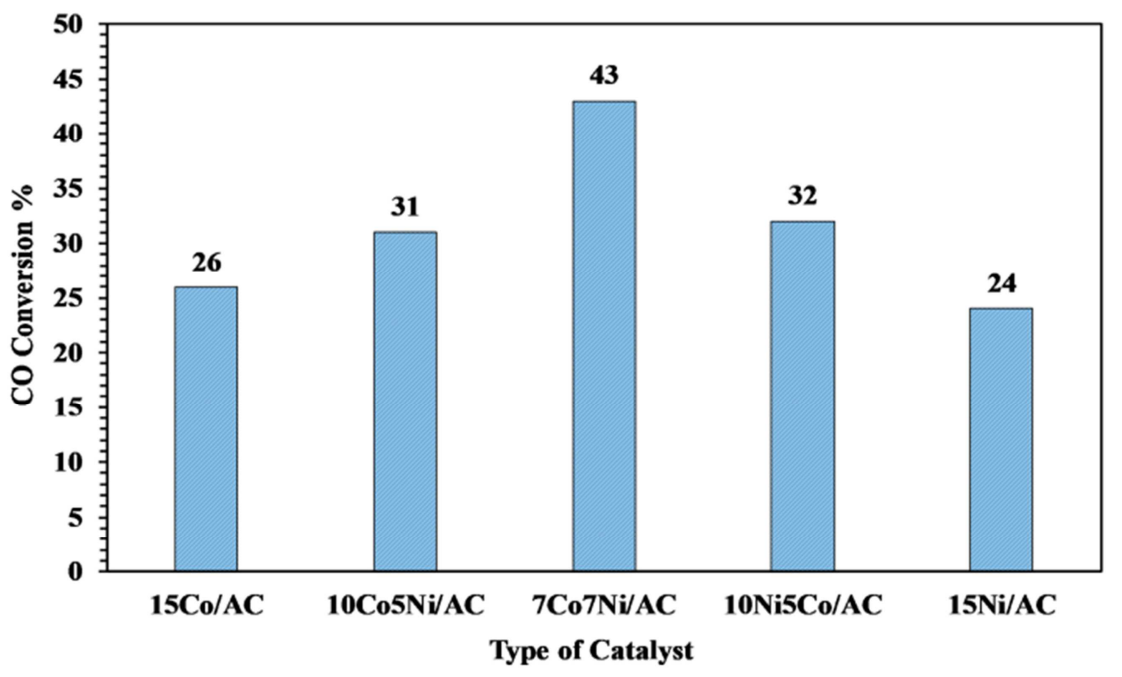

Figure 7. The effect of $\mathrm{Co}-\mathrm{Ni} / \mathrm{AC}$ bimetallic catalysts on\% CO conversion.

The hydrocarbon liquid product distribution achieved on the mono and bimetallic catalysts Co-Ni is shown in Figure 7 . All catalysts revealed hydrocarbon liquid products in the range of $C_{7}-C_{20}$. Selectivity to gasoline fraction $\left(C_{7}-C_{11}\right)$ was highly produced on the bimetallic catalysts compared to monometallic catalysts and decreased in the order of $7 \mathrm{Co} 7 \mathrm{Ni} / \mathrm{AC}(69 \%)>$ $10 \mathrm{Ni} 5 \mathrm{Co} / \mathrm{AC}(59 \%)>10 \mathrm{Co} 5 \mathrm{Ni} / \mathrm{AC}(40 \%)>15 \mathrm{Ni} / \mathrm{AC}(33 \%)>15 \mathrm{Co} / \mathrm{AC}(11 \%)$.

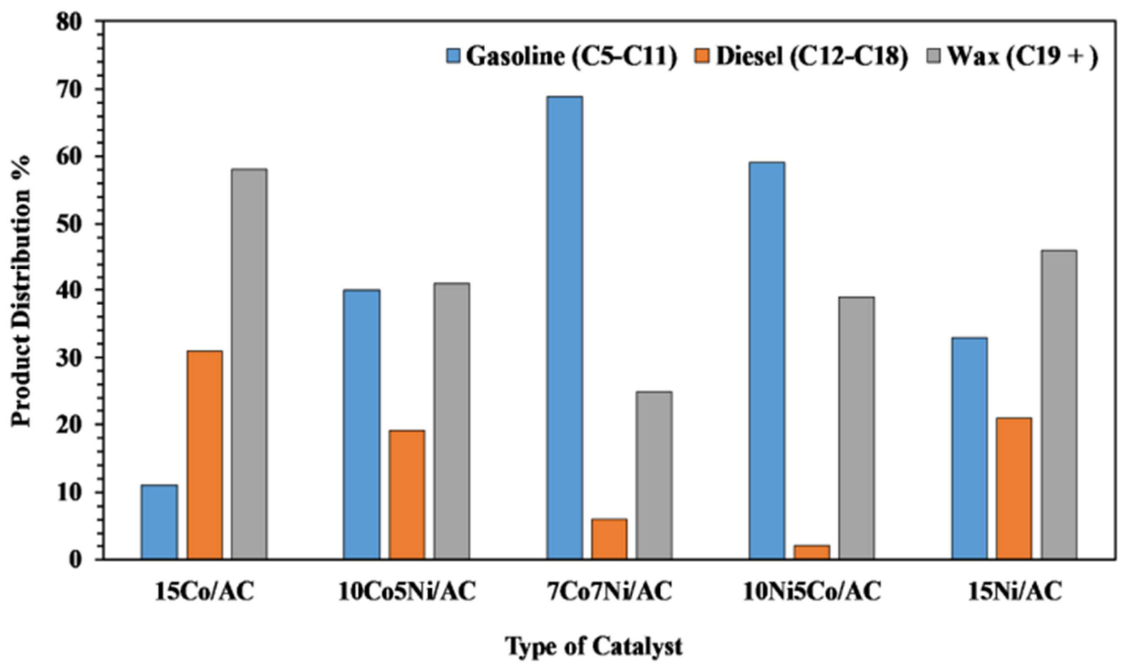

Figure 8. The effect of Co-Ni/AC bimetallic catalysts on the product distribution. 
Table 5. Product distribution and CO Conversion of the catalysts at reaction pressure $=(1$ bar $)$, reaction temperature $=\left(220^{\circ} \mathrm{C}\right), \mathrm{H}_{2} / \mathrm{CO}$ stoichiometric ratio $=(2)$.

\begin{tabular}{lllll}
\hline \multirow{2}{*}{ Catalyst } & \multicolumn{2}{l}{$\%$ Product Distribution } & \multicolumn{1}{l}{ CO } \\
& Gasoline & Diesel & Wax & Conversion \\
\hline $15 \mathrm{Co} / \mathrm{AC}$ & 11 & 31 & 58 & 26 \\
$10 \mathrm{Co} 5 \mathrm{Ni} / \mathrm{AC}$ & 40 & 19 & 41 & 31 \\
$7 \mathrm{Co} 7 \mathrm{Ni} / \mathrm{AC}$ & 69 & 6 & 25 & 43 \\
$10 \mathrm{Ni} 5 \mathrm{Co} / \mathrm{AC}$ & 59 & 2 & 39 & 32 \\
$15 \mathrm{Ni} / \mathrm{AC}$ & 33 & 21 & 46 & 24 \\
\hline
\end{tabular}

The effect of metal loading on the production of gasoline has also investigated previously by Ishihara and colleagues on the bimetallic $\mathrm{Co}-\mathrm{Ni}$ and $\mathrm{Co}-\mathrm{Fe}$ catalysts supported by $\mathrm{SiO} 2$. Increasing $\mathrm{Ni}$ loading from $25 \mathrm{wt} . \%$ to $50 \mathrm{wt} . \%$ has increased gasoline selectivity from $11.5 \%$ on monometallic $\mathrm{Co} / \mathrm{SiO}_{2}$ catalyst to $25 \%$ on $75 \mathrm{Co} 25 \mathrm{Ni} / \mathrm{SiO} 2$ catalyst reaching a maximum selectivity of $31.5 \%$ on $50 \mathrm{Co} 50 \mathrm{Ni} / \mathrm{SiO} 2$. $\mathrm{CO}$ conversion was also the maximum on the later catalyst. Further increasing of $\mathrm{Ni}$ on $25 \mathrm{Co} 75 \mathrm{Ni}$ has decreased selectivity to $23 \%$. The combination of Co-Ni catalysts was found better than $\mathrm{Co}-\mathrm{Fe}$ in terms of gasoline production. The author suggested that there is an optimum composition in every bimetallic system for production of desired hydrocarbons. In his case, the bimetallic catalyst $50 \mathrm{Co} 50 \mathrm{Ni} / \mathrm{SiO}_{2}$ was the most selective for production of gasoline fraction. The author attributed the results to the tendency of the catalyst to the formation of higher hydrocarbons as well as the enhanced activity for $\mathrm{CO}$ conversion. Furthermore, alloying of cobalt and nickel in the mentioned catalyst increased both the amount of adsorbed activated hydrogen and carbon monoxide on the surface and thus increased selectivity towards gasoline fraction [36]. Previous studies have shown that nickel active metal has a good ability to catalyse the hydrocracking of hydrocarbons [37]. The inclusion of $\mathrm{Ni}$ in the bimetallic catalysts with $\mathrm{Co}$ has played an important role in hydrocracking the heavier hydrocarbons and resulted in enrichment of lighter ones. It was found that increasing of $\mathrm{Ni}$ from $0.5 \mathrm{wt} . \%$ to 2 and 5 wt.\% in the bimetallic catalyst with Co has decreased the selectivity towards longer chain products $(\mathrm{C} 21+)$ and increased the selectivity towards short chain products [38]. It was suggested that there is a balance between the carbonchain growth on the Co active sites and the hydrocracking of heavier hydrocarbons on the $\mathrm{Ni}$ active sites, that maximizes the production of lighter liquid hydrocarbons. In other words, there is a degree of $\mathrm{Ni}$ metal existence in the catalyst which is required for maximizing the selectivity of the catalyst towards lighter hydrocarbons. In their case, the selectivity for lighter liquid hydrocarbons (C5 - C20) was significantly improved from $39 \%$ to the highest value of $62 \%$ on the bimetallic catalyst $\mathrm{Ni}-\mathrm{Co} / \mathrm{CNT}$ when the loading of $\mathrm{Ni}$ was 5 wt.\% [38]. The detailed hydrocarbon liquid products distribution for all prepared catalysts and the achieved CO conversion are listed in Table 5. In recent study, increasing $\mathrm{Ni}$ content from 5 to $7 \mathrm{wt} \%$ in the bimetallic catalyst $7 \mathrm{Co} 7 \mathrm{Ni} / \mathrm{AC}$ resulted in increased number of active sites which implied an increased number of $\mathrm{H}$ atoms through a high concentration of adsorbed hydrogen on the surface of the catalyst; eliminating the desorption of olefin accordingly and promoting the hydrogenation process to paraffin via improving olefin re-adsorption, leading to enhanced selectivity for gasoline.

\subsection{Optimization Study}

\subsubsection{The Effect of Reaction Temperature on $\mathrm{CO}$ Conversion and Gasoline Selectivity}

The influence of the reaction temperature on the best catalyst $7 \mathrm{Co} 7 \mathrm{Ni} / \mathrm{AC}$ at reaction temperature range of $220^{\circ} \mathrm{C}$. $300^{\circ} \mathrm{C}$, reaction pressure of 1 bar and $\mathrm{H}_{2}: \mathrm{CO}$ stoichiometric ratio of 2 was studied. It was found that reaction temperature has a significant effect on the $\mathrm{CO}$ conversion and gasoline selectivity. Increasing the reaction temperature from $220^{\circ} \mathrm{C}$ to 240, 260, 280 and $300^{\circ} \mathrm{C}$ resulted in increasing the $\mathrm{CO}$ conversion from $43 \%$ to values of $45 \%, 49 \%, 53 \%$ and $65 \%$, respectively, as shown in Figure 9. The improved conversion of $\mathrm{CO}$ at elevated reaction temperatures was attributed to the high dispersion of metal active phase into the support as metal dispersion has a major influence on activity and selectivity of the catalyst [39]. A decrease in CO conversion was attributed to the low metal dispersion in a previous study [40].

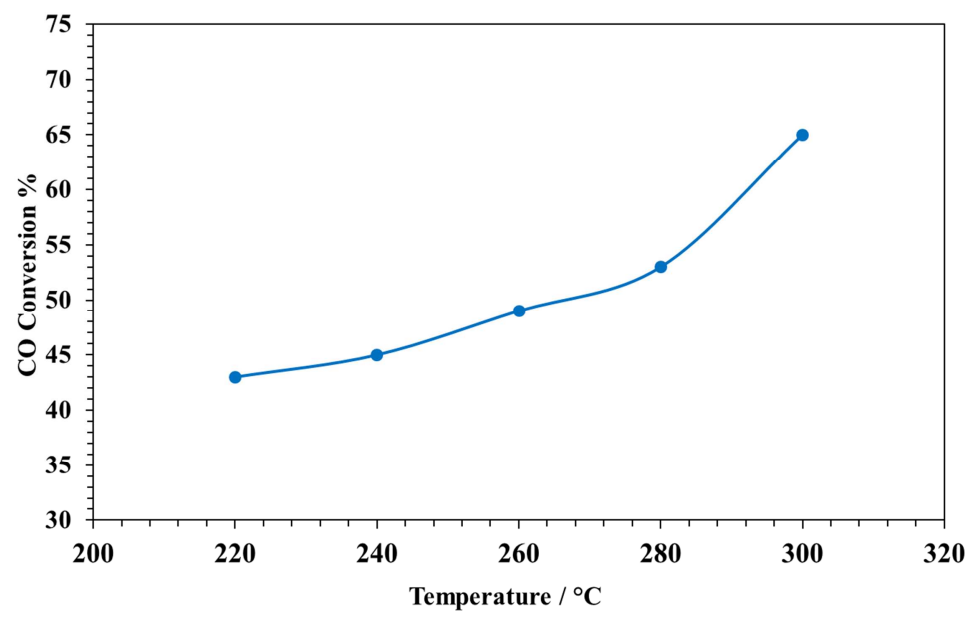

Figure 9. The influence of reaction temperature on $\mathrm{CO}$ conversion for $7 \mathrm{Co} 7 \mathrm{Ni} / \mathrm{AC}$ bimetallic catalyst. 
Increasing reaction temperature on the bimetallic catalyst $7 \mathrm{Co} 7 \mathrm{Ni} / \mathrm{AC}$ resulted in improved selectivity towards short hydrocarbon chain (gasoline fraction) and a decrease towards longer hydrocarbon components (diesel and wax fraction).
Gasoline fraction has increased at all elevated temperatures from $69 \%$ at $220^{\circ} \mathrm{C}$ to values of $73 \%, 75 \%, 86 \%$ and $92 \%$ at temperature values of $240^{\circ} \mathrm{C}, 260^{\circ} \mathrm{C}, 280^{\circ} \mathrm{C}$ and $300^{\circ} \mathrm{C}$, respectively, as shown in the Figure 10.

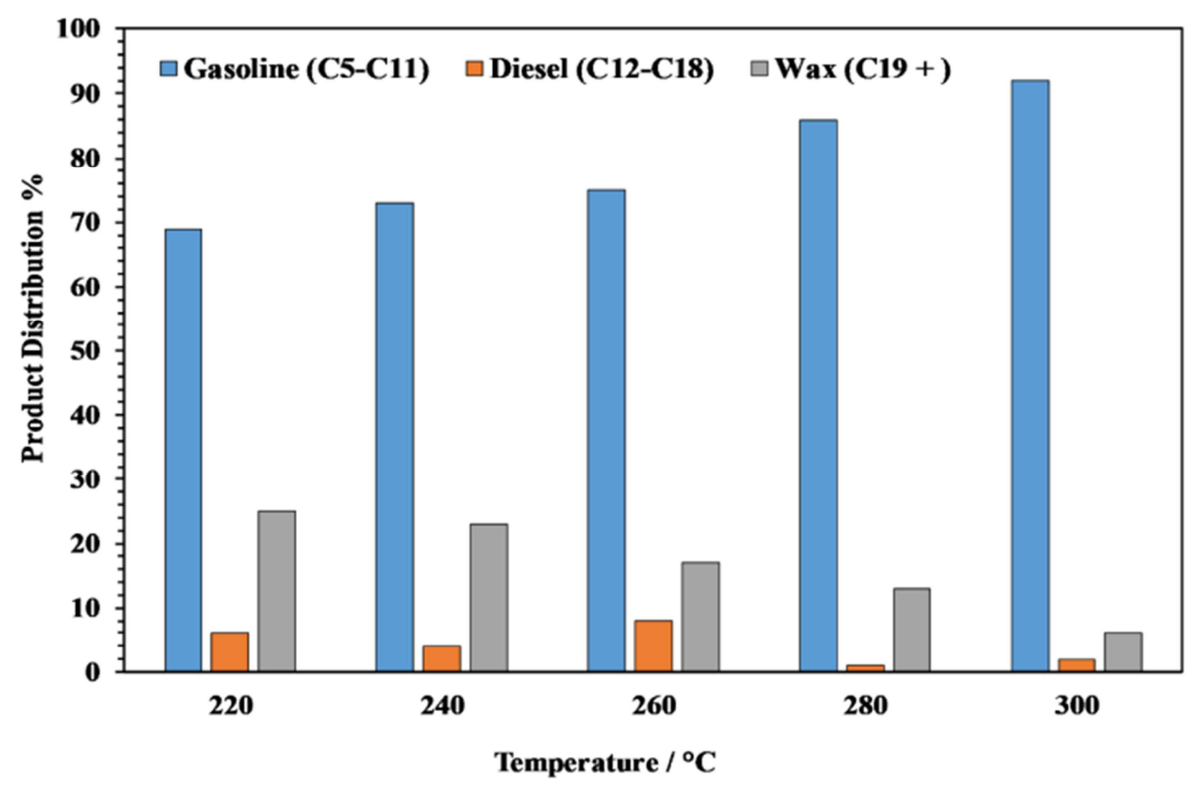

Figure 10. The influence of reaction temperature on the product distribution for the catalyst $7 \mathrm{Co} 7 \mathrm{Ni} / \mathrm{AC}$.

It was mentioned elsewhere, that since the bimetallic catalyst is found to be selective for a desired hydrocarbon product (in this case gasoline), then active sites are favouring the production of gasoline fraction increasingly at higher temperatures [39]. Increasing CO conversion and selectivity to lighter hydrocarbon products by increasing reaction temperature has also reported by other studies [41-43]. The chain growth probability equals the ratio of chain propagation reaction rate to the chain termination reaction rate. The reaction with higher activation energy will respond faster to the change of reaction temperature. Therefore, in the case of producing lighter hydrocarbon fraction at increased temperatures, it is believed that the chain termination reaction has the higher activation energy than the chain propagation reaction, resulted in decreasing the chain growth probability [43, 44]. Other study has mentioned that high temperature favours chain termination or desorption reactions since desorption is an endothermic process, so increasing temperature shifts selectivity towards lighter hydrocarbons [45]. It was also found that higher temperatures promote $\mathrm{CO}$ dissociation and provide more surface $\mathrm{C}$ atoms leading to the release of lighter hydrocarbons [46]. Optimal reaction conditions were also investigated on Co based catalyst supported on diamond carbon. Increase of reaction temperature from $\left(240^{\circ} \mathrm{C}-260^{\circ} \mathrm{C}\right)$ resulted in increased $\mathrm{CO}$ conversion as well as increased selectivity to lighter hydrocarbons. However, selectivity to heavy hydrocarbons were found to decrease with increasing reaction temperature. They attributed results to the tendency of the lower molecular mass compounds to increase with increasing reaction temperature [47].
The effect of reaction temperature on product distribution was also investigated in different study at 250,260, and $270^{\circ} \mathrm{C}$ on $\mathrm{Co}-\mathrm{Ni} / \mathrm{CNT}$. As a result, $\mathrm{CO}$ conversion increased with increasing temperature. Because the mobility of the hydrogen atom on the catalyst surface was promoted at higher temperatures resulted in enhanced $\mathrm{CO}$ conversion and light hydrocarbon production [31]. The hydrocracking of long chain hydrocarbons on $\mathrm{Ni}$ was improved with an increase in temperature, resulting in lighter and less heavy hydrocarbons as mentioned elsewhere. It was reported that, at a proper reaction temperature of $260^{\circ} \mathrm{C}$, the carbon chain growing on $\mathrm{Co}$ and the cracking on $\mathrm{Ni}$ reached a good balance to obtain the highest selectivity of liquid hydrocarbons [38]. Table 6 displays the detailed product distribution and $\mathrm{CO}$ conversion on $7 \mathrm{Co} 7 \mathrm{Ni} / \mathrm{AC}$ bimetallic catalyst.

Table 6. Product distribution and CO Conversion for the $7 \mathrm{Co} 7 \mathrm{Ni} / \mathrm{AC}$ bimetallic catalyst at reaction pressure $=(1$ bar $)$, reaction temperature $\left(220^{\circ} \mathrm{C}-300^{\circ} \mathrm{C}\right), \mathrm{H}_{2} / \mathrm{CO}$ stoichiometric ratio $=(2)$.

\begin{tabular}{lllll}
\hline \multirow{2}{*}{$\begin{array}{l}\text { Temperature } \\
\left({ }^{\circ} \mathbf{C}\right)\end{array}$} & \multicolumn{2}{l}{$\%$} & $\begin{array}{l}\text { \% Product Distribution } \\
\text { Conversion }\end{array}$ \\
\cline { 2 - 4 } & Gasoline & Diesel & Wax & \\
\hline 220 & 69 & 6 & 25 & 43 \\
240 & 73 & 4 & 23 & 45 \\
260 & 75 & 8 & 17 & 49 \\
280 & 86 & 1 & 13 & 53 \\
300 & 92 & 2 & 6 & 65 \\
\hline
\end{tabular}

\subsubsection{The Effect of Reaction Pressure on CO Conversion and Gasoline Selectivity}

The effect of reaction pressure on the best catalyst $7 \mathrm{Co} 7 \mathrm{Ni} / \mathrm{AC}$ at the best reaction temperature of $300^{\circ} \mathrm{C}$, $\mathrm{H}_{2}: \mathrm{CO}$ stoichiometric ratio of 2 and reaction pressure of $1-9$ 
bar, in terms of $\mathrm{CO}$ conversion and gasoline selectivity was investigated. It was found that the reaction pressure has a great impact on the distribution of hydrocarbon liquid products and $\mathrm{CO}$ conversion. Increasing the reaction pressure from 1 bar to elevated values of 3 bar, 5 bar, 7 bar and 9 bar resulted in increased CO conversion from $65 \%$ to $67 \%, 69 \%$, $74 \%$ and $84 \%$ as shown in Figure 11.

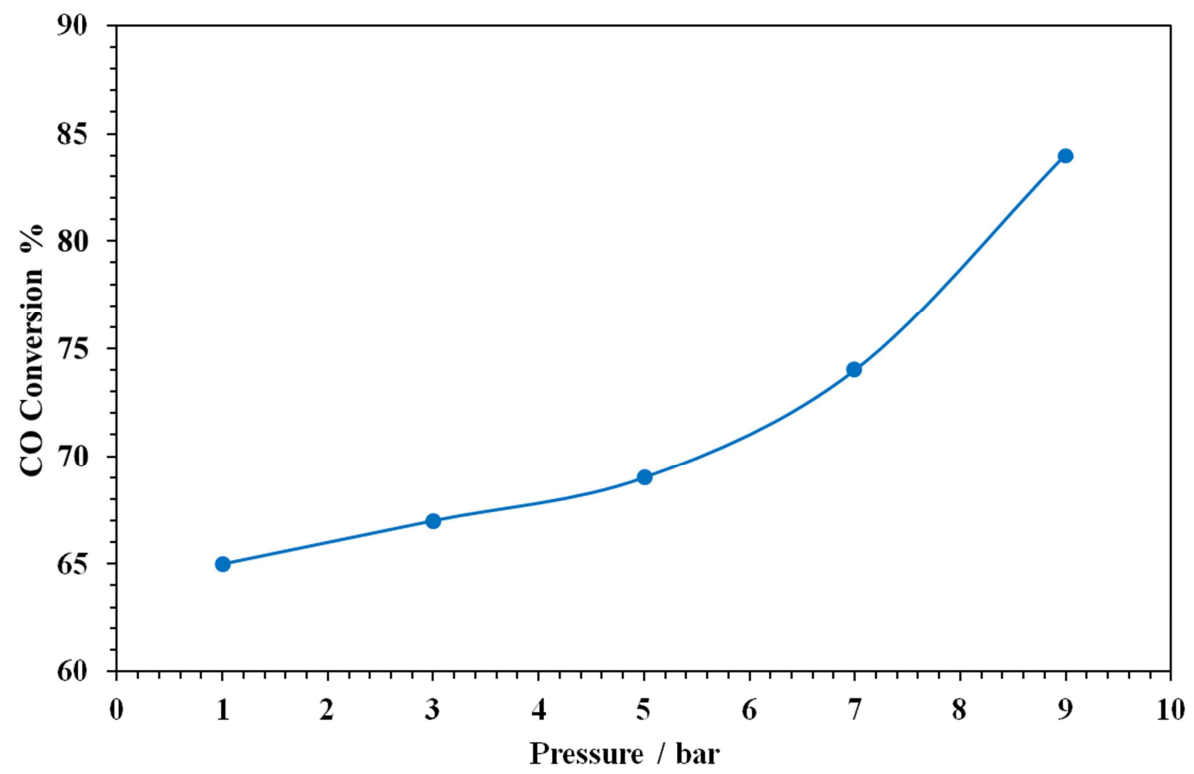

Figure 11. The influence of reaction pressure on CO conversion for $7 \mathrm{Co} 7 \mathrm{Ni} / \mathrm{AC}$ bimetallic catalyst.

On the other hand, increasing the reaction pressure on $7 \mathrm{Co} 7 \mathrm{Ni} / \mathrm{AC}$ bimetallic catalyst from 1 bar to higher values of 3 bar, 5 bar, 7 bar and 9 bar, resulted in a decrease in light hydrocarbon products (gasoline fraction) from $92 \%$ to $86 \%, 63 \%, 42 \%$ and $36 \%$, respectively and an increase in the heavier hydrocarbons (wax fraction) from $6 \%$ to $12 \%, 36 \%, 55 \%$ and $62 \%$, respectively, as shown in Figure 12.

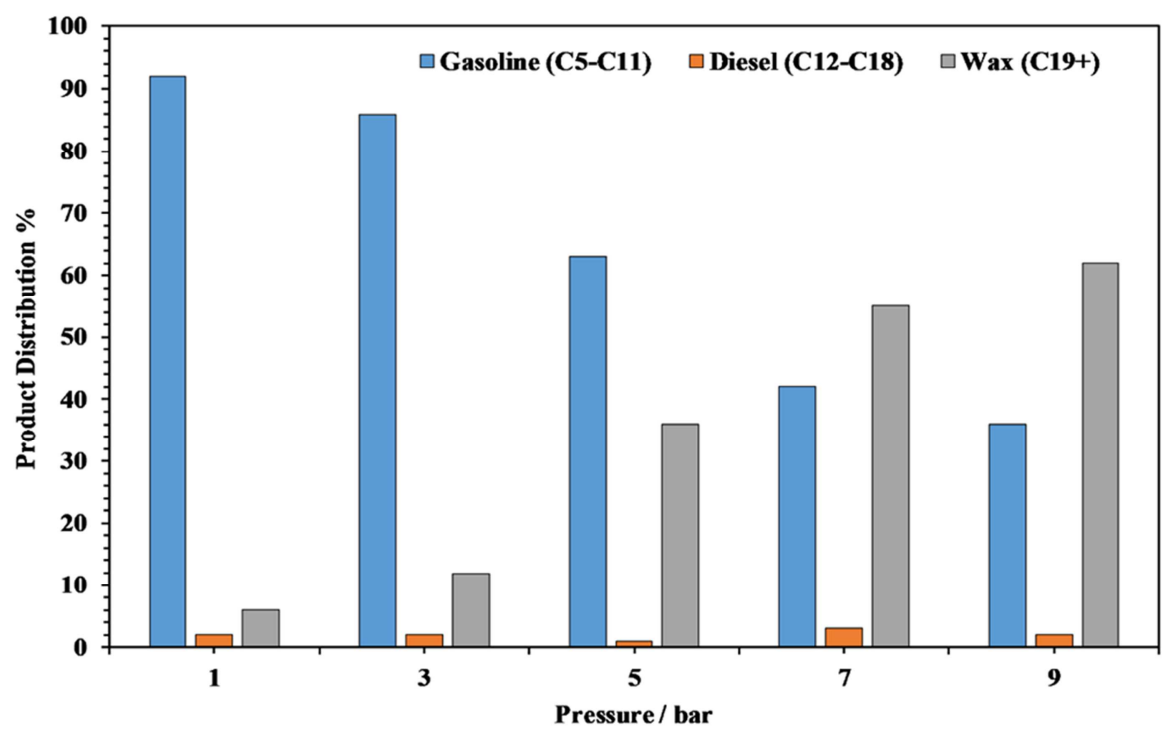

Figure 12. The influence of reaction pressure on the product distribution for the catalyst 7 Co $7 N i / A C$.

Similar behaviour was also reported by a group of researchers, when they mentioned an increase in both $\mathrm{CO}$ conversion and selectivity towards heavier hydrocarbon products at $350^{\circ} \mathrm{C}, \mathrm{H}_{2} / \mathrm{CO}=2 / 1$ and pressure range $1-10$ bar. $\mathrm{CO}$ conversion was found increasing greatly from $70 \%$ to $90 \%$ through increased reaction pressure. However, the increase in liquid hydrocarbon products selectivity was limited only from $5 \%$ to $20 \%$ [41]. In elsewhere study, it was reported that the increase of reaction pressure from 5 to 20 bar resulted in increased $\mathrm{CO}$ conversion from $23 \%$ to $47 \%$ as well as increased heavy hydrocarbon selectivity from $10 \%$ to $80 \%$. The author has ascribed the increase in CO conversion to the increase in partial pressure of hydrogen, since the rate of the reaction was reported to be proportional to the partial pressure of hydrogen [47]. It was suggested that higher pressure is preferred for the chain growth because increasing 
the pressure improves the diffusion probabilities of reactants into active metals on catalyst surface facilitating the production of long chain hydrocarbons [46]. The detailed hydrocarbon product distribution and $\mathrm{CO}$ conversion for $7 \mathrm{Co} 7 \mathrm{Ni} / \mathrm{AC}$ bimetallic catalyst is listed in Table 7 .

Table 7. The product distribution and CO Conversion for $7 \mathrm{Co} 7 \mathrm{Ni} / \mathrm{AC}$ bimetallic catalysts at reaction pressure $(1-9$ bar $)$, reaction temperature $=$ $\left(300^{\circ} \mathrm{C}\right), \mathrm{H}_{2} / \mathrm{CO}$ stoichiometric ratio $=(2)$.

\begin{tabular}{lllll}
\hline \multirow{2}{*}{$\begin{array}{l}\text { Pressure } \\
\text { (bar) }\end{array}$} & \multicolumn{2}{l}{ \% Product Distribution } & \multirow{2}{*}{$\begin{array}{l}\text { CO } \\
\text { Conversion }\end{array}$} \\
\cline { 2 - 4 } & Gasoline & Diesel & Wax & 65 \\
3 & 92 & 2 & 6 & 67 \\
5 & 86 & 2 & 12 & 69 \\
7 & 63 & 1 & 36 & 74 \\
9 & 42 & 3 & 55 & 84 \\
\hline
\end{tabular}

\section{Conclusion}

Inclusion of both cobalt and nickel active metals in a binary system catalyst supported by AC has significantly favored the production of liquid hydrocarbon fractions via Fischer-Tropsch reaction. The catalyst $7 \mathrm{Co} 7 \mathrm{Ni} / \mathrm{AC}$ was selected as the optimum catalyst among other prepared catalysts due to better catalytic activity in terms of gasoline production. The enhanced selectivity towards gasoline that has been achieved on the mentioned bimetallic catalyst was attributed to high degree of reduction, smaller crystallite size and high surface area of the catalyst. Possessing high degree of reduction has positively reflected on the reducibility of the catalyst meaning more active sites and better catalytic activity. Increasing the reaction temperature from $220^{\circ} \mathrm{C}$ to $300{ }^{\circ} \mathrm{C}$ has improved selectivity towards gasoline from $69 \%$ to $92 \%$ by weight and increased CO conversion from $43 \%$ to $65 \%$. Whereas, increasing total reaction pressure from 1 bar to 9 bar has led to decrease gasoline fraction from $92 \%$ to $36 \%$ towards heavier hydrocarbons and increase CO conversion from $65 \%$ to $84 \%$. The ability to catalyze hydrocracking of heavy hydrocarbons which Ni active sites possess, has been crucial in synthesizing gasoline fraction when mixed together with cobalt active metal in a binary system catalyst.

\section{References}

[1] R. Bechara, D. Balloy, and D. Vanhove, "Catalytic properties of $\mathrm{Co} / \mathrm{Al} 2 \mathrm{O} 3$ system for hydrocarbon synthesis," Appl. Catal. A Gen., vol. 207, no. 1-2, pp. 343-353, 2001.

[2] G. A. Alsultan, N. Asikin-Mijan, H. V. Lee, A. S. Albazzaz, and Y. H. Taufiq-Yap, "Deoxygenation of waste cooking to renewable diesel over walnut shell- derived nanorode activated carbon supported $\mathrm{CaO}-\mathrm{La} 2 \mathrm{O} 3$ catalyst," Energy Convers. Manag., vol. 151, 2017.

[3] G. Abdulkareem-alsultan, N. Asikin-mijan, H. V Lee, and Y. H. Taufiq-yap, "A new route for the synthesis of La-Ca oxide supported on nano activated carbon via vacuum impregnation method for one pot esterification- transesterification reaction," Chem. Eng. J., vol. 304, pp. 61-71, 2016.
[4] N. Asikin-Mijan, H. V. Lee, Y. H. Taufiq-Yap, G. AbdulkremAlsultan, M. S. Mastuli, and H. C. Ong, "Optimization study of $\mathrm{SiO} 2-\mathrm{A} 2 \mathrm{O} 3$ supported bifunctional acid-base $\mathrm{NiO}-\mathrm{CaO}$ for renewable fuel production using response surface methodology,” Energy Convers. Manag., no. November, 2016.

[5] Y. Yang, H. Xiang, Y. Xu, L. Bai, and Y. Li, "Effect of potassium promoter on precipitated iron-manganese catalyst for Fischer - Tropsch synthesis," vol. 266, pp. 181-194, 2004.

[6] Q. Tang, P. Wang, Q. Zhang, and Y. W. Ã, "Utilization of Microporous and Mesoporous Materials as Supports of Cobalt Catalysts for Regulating Product Distributions in Fischer Tropsch Synthesis," vol. 35, no. 4, pp. 9-10, 2006.

[7] K. Klaigaew, C. Samart, C. Chaiya, Y. Yoneyama, N. Tsubaki, and P. Reubroycharoen, "Effect of preparation methods on activation of cobalt catalyst supported on silica fiber for Fischer - Tropsch synthesis," Chem. Eng. J., 2014.

[8] T. T. Phadi, "Titanates and titania coated titanates as supports in the Fischer-Tropsch synthesis By Titanates and titania coated titanates as supports in the Fischer-Tropsch synthesis."

[9] X. Lu, P. H. D. Thesis, and X. Lu, "SYNTHESIS : TOWARDS UNDERSTANDING," 2011.

[10] K. Jalama, "Fischer Tropsch Synthesis over supported cobalt catalysts:Effect of ethanol addition, Precursors and gold doping, PhD thesis,University of the Witwatersrand," 2007.

[11] W. M. Hexana, "A systematic study of the effect of chemical promoters on the precipitated Fe-based Fischer-Tropsch Synthesis catalyst," 2009.

[12] A. Myriam and M. Motchelaho, "Iron and Cobalt Catalysts Supported on Carbon Nanotubes for Use in the FischerTropsch Synthesis," 2011.

[13] G. Abdulkreem-Alsultan, A. Islam, J. Janaun, M. S. Mastuli, and Y.-H. Taufiq-Yap, "Synthesis of structured carbon nanorods for efficient hydrogen storage," Mater. Lett., Sep. 2016.

[14] M. A. A. Aziz, A. A. Jalil, S. Triwahyono, and A. Ahmad, "ChemInform Abstract: CO2 Methanation over Heterogeneous Catalysts: Recent Progress and Future Prospects," no. May, 2015.

[15] T. Fu, Y. Jiang, J. Lv, and Z. Li, "Effect of carbon support on Fischer-Tropsch synthesis activity and product distribution over Co-based catalysts," Fuel Process. Technol., vol. 110, pp. 141-149, 2013.

[16] N. Asikin-mijan, H. V Lee, and Y. H. Taufiq-yap, "Chemical Engineering Research and Design Synthesis and catalytic activity of hydration - dehydration treated clamshell derived $\mathrm{CaO}$ for biodiesel production," Chem. Eng. Res. Des., vol. 102, pp. 368-377, 2015.

[17] A. A. Mirzaei, R. Habibpour, and E. Kashi, "Preparation and optimization of mixed iron cobalt oxide catalysts for conversion of synthesis gas to light olefins," Appl. Catal. A Gen., vol. 296, no. 2, pp. 222-231, 2005.

[18] H. Habazaki et al., "Co-methanation of carbon monoxide and carbon dioxide on supported nickel and cobalt catalysts prepared from amorphous alloys," Appl. Catal. a-General, vol. 172, no. 1, pp. 131-140, 1998. 
[19] A. A. Mirzaei, R. Sarani, H. R. Azizi, S. Vahid, and H. O. Torshizi, "Kinetics modeling of Fischer-Tropsch synthesis on the unsupported Fe-Co-Ni (ternary) catalyst prepared using co-precipitation procedure," Fuel, vol. 140, no. October, pp. 701-710, 2015

[20] X. Ma, Q. Sun, W. Ying, and D. Fang, "Effects of promoters on catalytic performance of $\mathrm{Fe}-\mathrm{Co} / \mathrm{SiO} 2$ catalyst for FischerTropsch synthesis," J. Nat. Gas Chem., vol. 18, no. 3, pp. 354-358, 2009.

[21] Z. Cheng-hua, Y. Yong, T. A. O. Zhi-chao, X. Hong-wei, and L. I. Yong-wang, "Structural properties and reduction behavior of Ni promoted FeMnK / SiO 2 catalysts for FischerTropsch synthesis," vol. 34, no. 6, pp. 2-6, 2006.

[22] T. Li, H. Wang, Y. Yang, H. Xiang, and Y. Li, "Study on an iron-nickel bimetallic Fischer-Tropsch synthesis catalyst," Fuel Process. Technol., vol. 118, pp. 1-8, 2014.

[23] A. Alsultan, A. Mijan, and T. Yap, "Preparation of Activated Carbon from Walnut Shell Doped La and Ca Catalyst for Biodiesel Production from Waste Cooking Oil," Mater. Sci. Forum, vol. 840, no. 3, pp. 348-352, 2016.

[24] K. K. Ramasamy, M. Gray, H. Job, and Y. Wang, "Direct syngas hydrogenation over a $\mathrm{Co}-\mathrm{Ni}$ bimetallic catalyst: Process parameter optimization," Chem. Eng. Sci., no. 2010, pp. 1-8, 2015.

[25] J. Thiessen, A. Rose, J. Meyer, A. Jess, and D. Curulla-ferré, "Microporous and Mesoporous Materials Effects of manganese and reduction promoters on carbon nanotube supported cobalt catalysts in Fischer - Tropsch synthesis," Microporous Mesoporous Mater., vol. 164, pp. 199-206, 2012.

[26] H. Reza, A. Akbar, M. Kaykhaii, and M. Mansouri, "Journal of Natural Gas Science and Engineering Fischer e Tropsch synthesis: Studies effect of reduction variables on the performance of Fe e Ni e Co catalyst," J. Nat. Gas Sci. Eng., vol. 18, pp. 484-491, 2014.

[27] A. Tavasoli, M. Trépanier, R. M. Malek Abbaslou, A. K. Dalai, and N. Abatzoglou, "Fischer-Tropsch synthesis on mono- and bimetallic Co and Fe catalysts supported on carbon nanotubes," Fuel Process. Technol., vol. 90, no. 12, pp. 14861494, 2009.

[28] J. A. Diaz et al., "Cobalt and iron supported on carbon nanofibers as catalysts for Fischer-Tropsch synthesis," Fuel Process. Technol., vol. 128, pp. 417-424, 2014.

[29] S. Ali, N. Mohd Zabidi, and D. Subbarao, "Correlation between Fischer-Tropsch catalytic activity and composition of catalysts," Chem. Cent. J., vol. 5, no. 1, p. 68, 2011.

[30] E. Rytter, T. H. Skagseth, S. Eri, and A. O. Sjåstad, "Cobalt Fischer - Tropsch Catalysts Using Nickel Promoter as a Rhenium Substitute to Suppress Deactivation,” pp. 4140 $4148,2010$.

[31] M. Trépanier, A. Tavasoli, A. K. Dalai, and N. Abatzoglou, "Fischer - Tropsch synthesis over carbon nanotubes supported cobalt catalysts in a fi xed bed reactor: In fl uence of acid treatment," Fuel Process. Technol., vol. 90, no. 3, pp. 367374, 2009.

[32] R. H. Hesas, A. Arami-niya, W. Mohd, A. Wan, and J. N. Sahu, "Preparation and Characterization of Activated Carbon," vol. 8, pp. 2950-2966, 2013.
[33] S. Qin, C. Zhang, J. Xu, Y. Yang, H. Xiang, and Y. Li, "Fe-Mo interactions and their influence on Fischer-Tropsch synthesis performance," Appl. Catal. A Gen., vol. 392, no. 1-2, pp. 118-126, 2011.

[34] O. Shea and V. A. De Pen, "Fischer - Tropsch synthesis on mono- and bimetallic $\mathrm{Co}$ and Fe catalysts in fixed-bed and slurry reactors," vol. 326, pp. 65-73, 2007.

[35] P. Nikparsa, A. L. I. A. Mirzaei, and R. Rauch, "Modification of Co / Al 2 O 3 Fischer - Tropsch Nanocatalysts by Adding Ni : A Kinetic Approach,” 2016.

[36] T. Ishihara, K. Eguchi, and H. Arai, "Hydrogenation of carbon monoxide over $\mathrm{SiO} 2$-supported $\mathrm{FeCo}, \mathrm{CoNi}$ and $\mathrm{NiFe}$ bimetallic catalysts," Appl. Catal., vol. 30, no. 2, pp. 225-238, 1987.

[37] R. De Haan, G. Joorst, E. Mokoena, and C. P. Nicolaides, "Non-sulfided nickel supported on silicated alumina as catalyst for the hydrocracking of $\mathrm{n}$-hexadecane and of ironbased Fischer-Tropsch wax,” vol. 327, pp. 247-254, 2007.

[38] S. Wang, Q. Yin, J. Guo, and L. Zhu, "In fl uence of Ni Promotion on Liquid Hydrocarbon Fuel Production over Co / CNT Catalysts," 2013.

[39] V. A. De La Peña O’Shea, M. C. Álvarez-Galván, J. M. Campos-Martin, N. N. Menéndez, J. D. Tornero, and J. L. G. Fierro, "Surface and structural features of Co-Fe oxide nanoparticles deposited on a silica substrate," Eur. J. Inorg. Chem., no. 24, pp. 5057-5068, 2006.

[40] R. C. Reuel and C. H. Bartholomew, "Effects of support and dispersion on the $\mathrm{CO}$ hydrogenation activity/selectivity properties of cobalt," J. Catal., vol. 85, no. 1, pp. 78-88, 1984.

[41] A. A. Mirzaei, A. B. babaei, M. Galavy, and A. Youssefi, "A silica supported Fe-Co bimetallic catalyst prepared by the sol/gel technique: Operating conditions, catalytic properties and characterization," Fuel Process. Technol., vol. 91, no. 3, pp. 335-347, 2010.

[42] M. Zaman, A. Khodadi, and Y. Mortazavi, "Fischer-Tropsch synthesis over cobalt dispersed on carbon nanotubes-based supports and activated carbon," Fuel Process. Technol., vol. 90, no. 10, pp. 1214-1219, 2009.

[43] L. Guczi et al., "CO hydrogenation over cobalt and iron catalysts supported over multiwall carbon nanotubes: Effect of preparation," J. Catal., vol. 244, no. 1, pp. 24-32, 2006.

[44] B. Todic, L. Nowicki, N. Nikacevic, and D. B. Bukur, "Fischer-Tropsch synthesis product selectivity over an industrial iron-based catalyst: Effect of process conditions," Catal. Today, vol. 261, pp. 28-39, 2016.

[45] Z. Yan, Z. Wang, D. B. Bukur, and D. W. Goodman, "Fischer - Tropsch synthesis on a model Co / SiO 2 catalyst," J. Catal., vol. 268, no. 2, pp. 196-200, 2009.

[46] S. Farzad, A. Rashidi, A. Haghtalab, and M. A. Mandegari, "Study of effective parameters in the Fischer Tropsch synthesis using monolithic CNT supported cobalt catalysts," Fuel, vol. 132, pp. 27-35, 2014.

[47] T. O. Honsho, T. Kitano, T. Miyake, and T. Suzuki, "FischerTropsch synthesis over Co-loaded oxidized diamond catalyst," Fuel, vol. 94, pp. 170-177, 2012. 